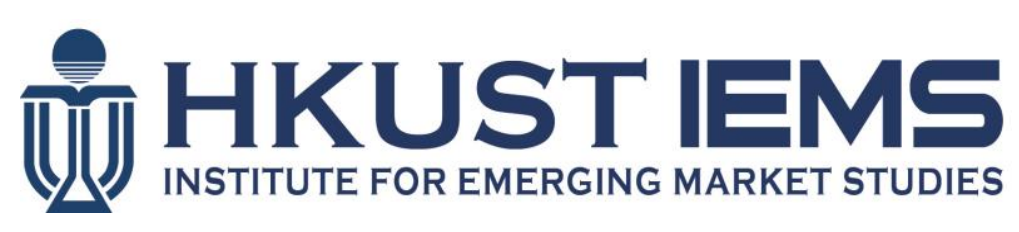

\title{
The Effect of Air Pollution on Mortality in China: Evidence from the 2008 Beijing Olympic Games
}

Guojun HE, Maoyong FAN, Maigeng ZHOU

HKUST IEMS Working Paper No. 2015-03

January 2015

HKUST IEMS working papers are distributed for discussion and comment purposes. The views expressed in these papers are those of the authors and do not necessarily represent the views of HKUST IEMS.

More HKUST IEMS working papers are available at: http://iems.ust.hk/WP 
The Effect of Air Pollution on Mortality in China: Evidence from the 2008 Beijing Olympic Games

Guojun HE, Maoyong FAN, Maigeng ZHOU

HKUST IEMS Working Paper No. 2015-03

January 2015

\begin{abstract}
By exploiting exogenous variation in air quality during the 2008 Beijing Olympic Games, we estimate the effect of air pollution on mortality in China. We find that a $10-\mu \mathrm{g} / \mathrm{m} 3$ (roughly $10 \%$ ) decrease in PM_10 concentrations reduces monthly standardized all-cause mortality by $6.63 \%$. The mortality reduction during the Olympics is mainly driven by fewer cardiocerebrovascular and respiratory deaths. Extrapolating our results to all urban areas in China, we estimate that the economic benefits from averted pre-mature deaths would range from 380 billion to 6 trillion Yuan annually if PM_10 concentrations were reduced to the WHO guideline level of $20 \mu \mathrm{g} / \mathrm{m}^{\wedge} 3$.
\end{abstract}

\title{
Author's contact information
}

Guojun He

Division of Social Science, Division of Environment, and Department of Economics The Hong Kong University of Science and Technology

E: gjhe@ust.hk

Maoyong Fan

Department of Economics

Ball State University

E: mfan@bsu.edu

Maigeng Zhou

National Center for Chronic and Noncommunicable Disease Control and Prevention Chinese Center for Disease Control and Prevention

E: maigengzhou@126.com 


\title{
The Effect of Air Pollution on Mortality in China: Evidence from the 2008 Beijing Olympic Games
}

\author{
Guojun $\mathrm{He}^{1}$, Maoyong Fan², Maigeng Zhou ${ }^{3}$
}

(January 2015)

\begin{abstract}
By exploiting exogenous variation in air quality during the 2008 Beijing Olympic Games, we estimate the effect of air pollution on mortality in China. We find that a $10-\mu \mathrm{g} / \mathrm{m}^{3}$ (roughly $10 \%$ ) decrease in $P M_{10}$ concentrations reduces monthly standardized all-cause mortality by $6.63 \%$. The mortality reduction during the Olympics is mainly driven by fewer cardiocerebrovascular and respiratory deaths. Extrapolating our results to all urban areas in China, we estimate that the economic benefits from averted pre-mature deaths would range from 380 billion to 6 trillion Yuan annually if $P M_{10}$ concentrations were reduced to the WHO guideline level of $20 \mu g / m^{3}$.
\end{abstract}

Keywords: Air Pollution, Mortality, Particulate Matter, 2008 Beijing Olympic Games JEL codes: Q53; I15; I18

${ }^{1}$ Division of Social Science, Division of Environment, and Department of Economics, The Hong Kong University of Science and Technology; Email: gjhe@ust.hk

${ }^{2}$ Department of Economics, Ball State University; Email: mfan@bsu.edu

${ }^{3}$ National Center for Chronic and Noncommunicable Disease Control and Prevention, Chinese Center for Disease Control and Prevention; Email: maigengzhou@126.com

We are indebted to Jeffrey Perloff, Michael Anderson, Meredith Fowlie, Peter Berck, William Dow, Elisabeth Sadoulet, Sofia Villas-Boas, Maximillian Auffhammer, Christian Treager, and seminar participants at UC Berkeley, Harvard, University of Chicago, HKUST, NBER, and 88th WEAI dissertation workshop for comments and suggestions. Guojun He also thanks the Pamela and Kenneth Fong Fellowship and IBER dissertation grant for financial support. All errors are our own. 


\section{The Effect of Air Pollution on Mortality in China: Evidence from the 2008 Beijing Olympic Games}

\section{Introduction}

Air pollution imposes significant health risks for humans in developing countries (among them the two largest China and India), where the levels of pollution are often several orders of magnitude higher than those in developed countries (Greenstone and Hanna forthcoming). Accurately estimating the effects of air pollution is critical for a national environmental policy design and implementation. Overestimating the air pollution effects will lead to over-regulation and hinder economic growth, while underestimating the air pollution effects will leave a large number of people unprotected and create significant and unnecessary economic welfare losses.

Several studies have shown that the air pollution effects estimated from associational approaches tend to be sensitive to model specifications, and that these estimates are likely to be biased because they fail to address the endogeneity issue of air pollution (Chay and Greenstone 2003a, b, Dominici, Greenstone, and Sunstein 2014, Schlenker and Walker 2011). In the short run, sharp variations in air pollution are influenced by meteorological factors such as temperature and precipitation. Because those factors also affect human health, failure to isolate the effects of air pollution from those of weather may result in substantial errors in the estimates of the effects of air pollution. In the long run, the consequences of air pollution can be confounded by a variety of socioeconomic conditions that cannot be easily accounted for. For instance, individuals living in areas with higher pollution may have worse health outcomes due to factors unrelated to pollution such as bad diets or smoking. People may also sort themselves into regions with 
different pollution levels on the basis of their preference for, or health responses to, ambient air pollution.

This study uses a unique quasi-experiment to estimate the causal effects of air pollution on mortality in China. Specifically, we explore the exogenous air pollution variations induced by the 2008 Beijing Olympic Games (BOG08). The strict enforcement of air pollution regulations by the Chinese government for the BOG08 caused a sudden and sharp decrease in air pollution in the cities hosting the Games during the period of regulation while unregulated cities did not experience similar changes. This provides a compelling setting for estimating the air pollution effects. By comparing the mortality rates in the regulated cities with those in the unregulated cities before, during, and after the BOG08, we find that air pollution has a large and significant effect on overall mortality, especially on cardio-cerebrovascular and respiratory mortality, in China.

We make four primary contributions to the existing literature. First, while many previous quasi-experimental designs investigated the effects of permanent policy changes on air pollution (Chay and Greenstone 2003b, Chay, Dobkin, and Greenstone 2003), our study explores the air quality variations triggered by temporary yet strictly-enforced regulations. The exogeneity of permanent air pollution regulations such as the Clean Air Act in the United States is potentially problematic because, as citizens become aware of the potential health consequences of current levels of pollution, they put political pressure on government to create specific policy instruments to respond to their concerns. In cities where people are more health conscious, the enforcement of air quality regulations might be stricter and the subsequent health improvements might be larger. In contrast, the strong pressure to improve air quality during the BOG08 came from the international community. Air pollution in Beijing was the biggest concern of the 
International Olympic Committee during the bidding process for the 2008 Summer Olympic Games. The commitment to ensure good air quality in the Beijing metropolitan area and cohosting cities during the BOG08 was key to winning the bid; it became an important political task for the Chinese government. Starting from late 2007, the Chinese government implemented a series of stringent policies to reduce local and regional emissions in the greater Beijing metropolitan area to ensure good air quality during the BOG08. Among the aggressive regulations were: setting higher emission standards, reducing traffic, halting large-scale construction projects, and shutting down polluting factories. The combination of these radical measures resulted in a dramatic improvement in air quality in Beijing, its neighboring cities, and the co-host cities. The enforcement of the BOG08 regulations was strict, dramatic, and likely to be exogenous.

Second, to our knowledge, this study is the first to show the causal health effects of $\mathrm{PM}_{10}$ concentrations on a national scale in China. We combine a 5-year-long monthly mortality data with monthly air pollution data ( $P M_{10}$ concentrations) for 34 large Chinese cities that encompass much of China’s geography. Our estimates show that the improved air quality during the BOG08 significantly decreased mortality in regulated cities. Specifically, a $10-\mu g / \mathrm{m}^{3}$ (roughly 10 percent) reduction in monthly $P M_{10}$ concentrations would lead to approximately 2.37 fewer deaths per 100,000 people per month (6.63 percent decrease relative to its mean). Based on our estimates, more than 196,000 premature deaths in urban China could be averted if $P M_{10}$ concentrations were to decrease by $10 \mu \mathrm{g} / \mathrm{m}^{3}$ from the current level (approximately $98 \mathrm{\mu g} / \mathrm{m}^{3}$ on average). If the current $P M_{10}$ concentrations were reduced to the World Health Organization (WHO) guideline $P M_{10}$ level $-20 \mu \mathrm{g} / \mathrm{m}^{3}$, nearly 1.57 million pre-mature deaths in urban China could be averted each year. This number is substantially larger than the estimates from the 
Global Burden of Disease Study (Kassebaum et al. 2014) and OECD (2012). Combining our estimates with various estimates of the value of a statistical life in China, we find that the economic benefit associated with the pollution abatement ranges from 380 billion to 6 trillion Yuan annually.

Third, we are able to identify the heterogeneous effects of particulate matter pollution by exploring how air pollution affected mortalities from different types of illnesses. Patients with certain types of diseases might be more vulnerable to air pollution than others. We find that air pollution has a significant negative effect on the mortality rate of cardio-cerebrovascular and respiratory (CVR) patients. In contrast, the mortality rate of non-CVR patients are unaffected by air pollution. Based on our estimates, if the current level of average $P M_{10}$ concentrations were reduced by $10 \mu \mathrm{g} / \mathrm{m}^{3}$, the monthly CVR mortality rate would decrease by approximately 10.2 percent.

Finally, we present a variety of different specifications and find that they do not alter our conclusions. Weather conditions (temperature and precipitation) and socioeconomic characteristics, which are typically confounding factors in associational studies, have little effects on our estimates. We conduct falsification tests that use air-pollution-irrelevant (such as cancer and injury) death rates and find no evidence that the main findings are due to model choice or the underlying overall death patterns. We also show that cross-sectional or fixedeffects models are likely to suffer from omitted variables bias or attenuation bias, and that the estimates may be biased downward. We compare our instrumental variable estimates with those in the literature, and find that our estimates are comparable to those from long-term cohort studies, but are substantially larger than those from conventional short-term time-series studies. 
The remainder of this paper is laid out as follows. Section II reviews the literature on estimating the health effects of air pollution. Section III discusses the air pollution regulations during the BOG08. Section IV describes the air quality data, mortality data, and meteorological data. Section V addresses our research design and model. Section VI summarizes the main results, and Section VII checks their robustness. Section VIII compares our results with those of traditional models and previous studies, and Section IX provides a range of estimates on the monetary value of the averted deaths. Section X concludes.

\section{Health Effects of Air Pollution}

The association between air pollution and human health has been recognized for more than half a century. ${ }^{1}$ Previous studies can be roughly grouped into the following categories: (1) time-series studies; (2) cross-sectional and cohort-based studies; (3) panel (fixed-effects) studies; and (4) natural or quasi-experimental studies.

Time-series studies investigate whether daily or weekly fluctuations in air pollution are associated with changes in health outcomes (such as hospital admissions or deaths). Time series models are widely used by bio-statisticians and epidemiologists. Most of these studies find that temporary elevations in air pollution are associated with worse health outcomes (Bell, Samet, and Dominici 2004). However, sharp changes in air pollution levels are often driven by local weather conditions rather than by changes in polluting activities (Chay, Dobkin, and Greenstone 2003). If weather conditions cause health problems through other channels, it is unclear whether the poorer health outcomes are caused by elevated air pollution or by other risk factors. ${ }^{2}$

\footnotetext{
${ }^{1}$ For example, during the London fog incident of 1952, extreme elevations of air pollution were found to be associated with markedly increased mortality rates (Logan 1953).

${ }^{2}$ For example, Beijing's smoggy days in 2013, which were intensively reported by the mass media, largely resulted from the combined effects of temperature, humidity, and wind. Most of these smoggy days occurred on cold days with light wind. If people are more likely to die from
} 
Moreover, because there are no appropriate control groups, it is difficult to rule out alternative explanations in nearly all time-series studies.

Cross-sectional studies compare health outcomes across locations, examining how air pollution is associated with health outcomes after controlling for potential confounding factors. This type of research design is plagued by omitted variables bias. As people's health status and the local air quality are usually simultaneously determined by many other social and economic factors, a correlation between air pollution and health status does not necessarily indicate a causal relationship. In practice, it is infeasible to control for all potential confounding factors; thus, the health effect of air pollution estimated from cross-sectional models may be biased.

Cohort-based longitudinal studies (e.g. Dockery et al. 1993) may face problems similar to those of cross-sectional studies. In principle, longitudinal studies can accurately estimate the reduction in life expectancy associated with higher levels of pollution because they collect data on long-term exposure. However, to some extent, people self-select into different locations; thus, their exposure to different levels of pollution is endogenous. Wealthy people, whose health status tends to be good for other reasons, can migrate to clean regions, while poor people may be confined to polluted areas. Hence, the observed association between air quality and mortality may result from factors other than air pollution. As suggested by Chay and Greenstone (2003b, 2003a), these associational approaches tend to produce unreliable estimates.

As longitudinal data become increasingly available, recent studies have used fixed-effects models to deal with potential bias caused by time-invariant unobserved factors (Currie and Neidell 2005, Currie, Neidell, and Schmieder 2009). Fixed-effects models are particularly useful when time-invariant omitted factors explain most of the variations in an outcome variable. The

cold weather, the association between air pollution and increased mortality can be misleading unless these factors are fully controlled for. 
assumption required for identification is that there are no unobserved shocks to air pollution levels that co-vary with unobserved shocks to health outcomes. However, because changes in air quality often depend on factors similar to those affecting health outcomes (such as weather), this assumption may not hold. In addition, measurement error of air pollution is common in applied research. It may attenuate the marginal impact of air pollution and inflate the equation error variance in the fixed-effects models (Wansbeek and Meijer 2000).

In contrast, natural or quasi-experiments provide compelling identification strategies (Chay and Greenstone 2003b, a). Most quasi-experimental evidence on the health impact of air pollution has been based on settings in developed countries, and the majority of economic research focuses on the health of infants rather than the general population. Chay and Greenstone (2003a) analyzed the effects of the Clean Air Act Amendments on infant mortality, using nonattainment status as an instrument for Total Suspended Particulates (TSPs) changes. They estimated that a 1-percent decline in TSPs resulted in a 0.5-percent decline in the infant mortality rate. Chay and Greenstone (2003b) also explored how air quality improvement as a result of the 1981-1982 recession affected infant mortality in the United States. They find that a 1-percent reduction in TSPs resulted in a 0.35-percent decline in the infant mortality rate at the county level. Luechinger (2010) investigated the effect of $\mathrm{SO}_{2}$ on infant mortality in Germany, utilizing a natural experiment made possible by the mandated desulfurization of power plants, with wind directions dividing counties into treatment and control groups.

The results for adult health are mixed. For example, using the Clean Air Act as an instrumental variable for air quality, Chay, Dobkin, and Greenstone (2003) found that, although air pollution regulations were associated with large reductions in TSPs, such reductions had little effect on either adult or elderly mortality. Schlenker and Walker (2011) estimated the health 
effects of air pollution due to airline network delays in the United States and found that carbon monoxide $(\mathrm{CO})$ exposure led to significant increases in hospitalization rates for asthma and respiratory diseases and in heart-related emergency room admissions that were an order of magnitude higher than conventional estimates. The effects were statistically significant for infants, the elderly, and the adult population.

The evidence from developed countries has limited external validity for several reasons. First, the dose-response relationship between pollution and health might be non-linear, and is still not clear to researchers (Arceo-Gomez, Hanna, and Oliva 2012). Estimates derived from the United States and other developed countries may not be a good reference for developing countries' regulations. Second, avoidance behavior can mitigate the air pollution effect. The costs associated with avoidance behavior are relatively higher in the developing countries (Graff Zivin and Neidell 2009, Moretti and Neidell 2011), so the air pollution effect may differ. Third, the air pollution effect might be related to socioeconomic gradients in health (Jayachandran 2009). Lower income, poorer medical services, and less immediate emergency care may all contribute to a different (perhaps larger) air pollution effect in developing countries.

Studies linking air pollution exposure to health in the developing countries are rare. There are two major challenges. First, good quality air pollution and health data are difficult to come by in developing countries because of limited financial support for data collection, less coordinated government efforts, and fragmented data storage and computerization. Second, individual's exposure to air pollution is not randomly assigned and a good identification strategy such as a natural experiment is hard to find. In an analysis of the effects of air quality (particulate matter) in Indonesia on infant and child mortality, Jayachandran (2009) found that the increased pollution from wildfires accounted for 15,600 missing children. Greenstone and Hanna (2014) 
studied India's pollution regulations, and found that the most successful one resulted in a modest but statistically insignificant decline in infant mortality. As for China, Chen, Ebenstein, et al. (2013) estimated the long-term effect of air pollution on life expectancy, using China's winter heating policy as a natural experiment. They found that an increase in TSP concentration of 100 $\mu \mathrm{g} / \mathrm{m}^{3}$ led to a reduction in life expectancy at birth of about three years, and that the winter heating policy caused the 500 million residents of Northern China to lose more than 2.5 billion years of life expectancy. Rich et al. (2012) explored BOG08 and found that air quality improvement was associated with better health outcomes of young adults in Beijing during the Games. This study complements the long-term study (Chen, Ebenstein, et al. 2013) by providing insights on how monthly variations in air pollution would affect mortality. The identification strategy we use in this study improves on the research design in Rich et al. (2012) since we explore both over-time and cross-sites changes in air pollution levels and health outcomes.

\section{Air Pollution Regulations during the BOG08}

The air pollution controls enforced during the BOG08 may be by far the largest efforts made in human history to control air quality for a short period of time (Chen, Jin, et al. 2013). To ensure good air quality during the BOG08, the Chinese government implemented a series of radical pollution regulations starting in late 2007.

In October 2007, the State Council of China issued "Measures to Ensure Good Air Quality in the 29th Beijing Olympics and Paralympics.” The Measures defined the period from November 1, 2007 to July 20, 2008 as the pre-Olympic Comprehensive Regulation period and the period from July 20 to September 20, 2008 as the Olympic Games Temporary Pollution Control period. 
During the pre-Olympic Comprehensive Regulation period, multiple regulations were implemented simultaneously: (1) all coal-fired power plants in Beijing were required to install desulfurization, dust removal, and denitrification facilities; (2) the public sectors (public transit, environment and health agencies, etc.) replaced all heavy-emission vehicles; (3) oil-gas gathering units and recovery systems were installed at gas stations, oil storage facilities, and tankers; (4) the Second Beijing Chemical Plant, the Beijing Eastern Petrochemical Company, and several other polluting factories were completely shut down; (5) the government raised gas prices twice, in November 2007 and June 2008, to discourage auto vehicle usage; and (6) the Capital Steel Company was ordered to relocate, and its production of steel fell from more than 600,000 tons per day to less than 200,000 tons per day.

Motor vehicle exhaust emissions are the largest air pollution source in large cities. To further ensure good air quality, Beijing implemented temporary traffic controls during the Olympic Games Temporary Pollution Control period. From July 1 to September 20, 2008, vehicles with yellow environmental labels (vehicles that failed to meet the European No. I standards for exhaust emissions) were banned from Beijing's roads. As a consequence, more than 300,000 heavy-emission vehicles (mostly trucks, tractors, low-speed cargo trucks, triwheeled motor vehicles, and motorcycles) were not allowed on the roads. From July 20 to September 20, 2008, vehicles with odd-numbered (even-numbered) license plates were allowed on the roads only on odd-numbered (even-numbered) days. Police vehicles, public transport, vehicles with Olympic passes, and a few others were exempted from the odd-even plate rule. This policy reduced the number of vehicles on the public roads of Beijing by two million vehicles per day. According to the committee of the BOG08 and the Ministry of Environmental Protection (MEP) in China (2008), total vehicle exhaust emissions decreased by more than 60 
percent. ${ }^{3}$ Traffic controls significantly decreased the concentrations of fine particulates, ozone, nitrogen oxide, and other pollutants generated by auto vehicles in Beijing.

At the same time, the government required all power plants and chemical production plants to reduce their emissions by 30 percent from previous levels, although these plants were within the national emission standard to begin with. More than 20 cement production factories, more than 140 concrete mixing plants, and more than 100 lime production sites were completely shut down. To further reduce particulate matter pollution, the Chinese government also halted all construction projects during the BOG08.

Because air quality in Beijing was also affected by its neighboring areas, several cities and provinces (Tianjin, Hebei, Liaoning, Neimenggu, and Shanxi) around Beijing were also required to enforce the central government's emission control plans. All these provinces were required to retire outdated production facilities in power plants and to install desulfurization facilities. Factories were forced to reduce their production or temporarily shut down if they could not meet the national standard before June 2008. As some Olympic soccer games were held in Tianjin, Shenyang and Qinhuangdao, similar air pollution controls were implemented in these cities as well. For example, Tianjin shut down many polluting factories before the BOG08 and enforced temporary traffic control during the BOG08. Shenyang replaced old buses prior to the Olympics and expanded green belts around construction sites. Qinhuangdao built shelter forests along the piers to reduce dust, hosed down the streets with water, and transported garbage to the landfills/incinerators every day.

The combination of these regulations effectively improved air quality in and around Beijing. Our data show that the yearly $P M_{10}$ concentrations in Beijing decreased from 152

\footnotetext{
${ }^{3}$ http://www.bj.xinhuanet.com/bjpd_2008/2008-09/22/content_14462703.htm.
} 
$\mu \mathrm{g} / \mathrm{m}^{3}$ to $124 \mathrm{\mu g} / \mathrm{m}^{3}$ (an 18-percent decrease). The improvement was particularly striking during the summer period (June-August). The summer monthly $P M_{10}$ concentations decreased from $145 \mu \mathrm{g} / \mathrm{m}^{3}$ in 2007 to $101 \mu \mathrm{g} / \mathrm{m}^{3}$ in 2008, which corresponds to a 30-percent change in monthly air pollution levels. During the 17 days of the BOG08, all indicators of air quality in Beijing met national standards.

The air quality improvements were confirmed by multiple studies, such as the United Nations Environment Programme (2009) and Chen, Jin, et al. (2013). The United Nations Environment Programme (2009) examined the air pollution data provided by the Beijing Environmental Protection Bureau and found that air quality in Beijing met the national standard less than 50 percent of the time in 2000 but more than 75 percent of the time in 2008. Through analysis of satellite images during the month of August from 2005 to 2008, the United Nations Environment Programme (2009) showed that $\mathrm{CO}$ and $\mathrm{NO}_{2}$ concentrations decreased significantly, with $\mathrm{NO}_{2}$ levels, for example, falling by 50 percent from 2005 to 2008 . Chen, Jin, et al. (2013) evaluated the impact of the BOG08 on Beijing's air quality and found that the regulations effectively reduced the Air Pollution Index (API) by 30 percent in Beijing during July and August of 2008 (the BOG08 period) from a year ago. They also confirmed the improvement in air quality in Beijing using satellite-based Aerosol Optical Depth data.

\section{Data}

\section{A. Air Quality Data}

Air Quality data come from monitoring sites administered by the MEP in China, which has been providing daily air quality information for 82 major cities in China since 2000. Our air quality data include information on the daily API and the primary pollutant. The API is an index for 
reporting daily air quality to the general public. ${ }^{4}$ It is an overall measure of ambient air quality. A higher API score indicates a higher level of air pollution. Three individual pollutants, $\mathrm{PM}_{10}, \mathrm{SO}_{2}$ and $\mathrm{NO}_{2}$, are used to construct the API. Ideally, we would obtain the concentrations of each air pollutant. However, specific pollutant concentrations are not publicly available. Fortunately, the method used by the MEP to construct the API allows us to recover the concentrations of the primary pollutant. In the daily API data, $P M_{10}$ is the primary pollutant for 90 percent of our daily samples. As a consequence, we are able to recover the average monthly $P M_{10}$ concentrations from the API with high accuracy. The details of calculating $P M_{10}$ concentrations using the API are presented in Appendix A.

\section{B. Mortality Data}

Mortality data come from the Disease Surveillance Point System (DSPS) of the Chinese Center for Disease Control and Prevention (CDC). The DSPS was established by the Chinese government back in 1978 to provide timely information on the cause of death and number of deaths. For a selected surveillance point (either a county or a city-district), the DSPS collects data on all deaths in hospitals or at home. To represent national population and mortality trends, the DSPS adopts a multi-stage cluster population probability sampling method. The main objectives of the DSPS are to: (1) identify the number of deaths related to each disease category

\footnotetext{
${ }^{4}$ The reliability of official Chinese air quality data has been questioned by researchers. The government's unwillingness to publicize specific concentrations of pollutants makes it even more difficult for researchers to verify the reliability of the data. Chen et al. (2012) assessed the quality of China's API data and found a discontinuity at the threshold of 100 owing to the fact that a day with an API value of 100 or less is called a "blue-sky day," a threshold that local governments are incentivized to manipulate their data around. Nevertheless, Chen et al. (2012) found that the API is strongly correlated with NASA's Aerosol Optical Depth data and the China Meteorological Administration's visibility data; and such correlations do not change significantly when the API is just above or below 100. They concluded that, although the number of blue-sky days may be subject to data manipulation, the reported API did contain useful information on cross-city and over-time variations in air pollution.
} 
and provide basic mortality information about the deceased for public health officials; and (2) provide feedback to evaluate the impacts of the public health interventions. The DSPS initially covered 71 counties and city-districts in 29 provinces; this was expanded to 145 counties and city-districts in 31 provinces in 1990. The DSPS was overhauled following the SARS outbreak in 2003 and 161 counties and city-districts are designated in the system from 2004 to the present. Currently the DSPS covers more than 81.5 million people or roughly 6 percent of the Chinese population.

According to the epidemiological literature, we divide all deaths into two large categories by the cause of death: air-pollution-related deaths and air-pollution-irrelevant deaths. Airpollution-related deaths are those caused by cardio-cerebrovascular diseases and respiratory (CVR) diseases, and air-pollution-irrelevant deaths are those caused by cancer, digestive diseases, injuries, and other diseases. ${ }^{5}$ The monthly-standardized mortality rate is defined as the number of deaths per 100,000 people per month in a designated DSPS area, adjusted by the age distribution. ${ }^{6}$

We match mortality data with air pollution data at the monthly level and end up with 34 urban city-districts in both data sets. Figure 1 shows the geographical locations of these cities; they are dispersed over 26 provinces and encompass much of China’s geography. The population of all these cities totals more than 200 million people. The red marks are treatment cities, while the blues marks are control cities. This study focuses on a five-year window, from January 2006 to December 2010. The average monthly standardized mortality rate is 35.75 deaths per 100,000

\footnotetext{
${ }^{5}$ Even though some cancers are associated with exposure to air pollution, we think cancer mortality still works as a valid falsification test because the gestation periods for most cancers are much longer than the time period covered by our study.

${ }^{6}$ See Appendix B on how to calculate the standardized mortality rate.
} 
people per month, with a standard deviation of 13.72. The monthly standardized CVR mortality rate is 16.11 per 100,000 people, with a standard deviation of 7.63.

\section{Weather Data}

Data on temperature and precipitation are drawn from the Global Historical Climatology Network (GHCN) project. ${ }^{7}$ GHCN provides average monthly temperatures and precipitation levels for given longitudes and latitudes, with a minimum cell size of 0.5 degrees by 0.5 degrees.

For each city-district in our sample, we identify four nearest points out of the GHCN gridded data points for the entire globe based on geographical distance. We then calculate weighted averages of temperature and precipitation, using inverse squared distances as weights. For example, the precipitation of location $j$, using the nearest four points, is calculated as:

$$
\operatorname{Precip}_{j}=\sum_{k=1}^{4} \frac{\text { Precip }_{k} * \text { Distance }_{j k}^{-2}}{\sum_{k=1}^{4} \text { Distance }_{j k}^{-2}}
$$

where $\operatorname{Precip}_{j}$ is precipitation at point $j$, and Distance ${ }_{j k}^{-2}$ is the inverse squared distance between $j$ and $k$. Summary statistics of the key variables are provided in Table 1.

\section{Research Design and Model}

Our analysis compares changes in mortality rates in cities that experienced large reductions in $P M_{10}$ with changes in cities that experienced little or no reduction in pollution. We estimate the effects of air pollution on mortality using a fixed-effects instrumental variable model:

$$
Y_{i t}=\delta_{0} \hat{P}_{i t}+X_{i t}^{\prime} \eta_{0}+u_{i}+v_{t}+\varepsilon_{i t}
$$

${ }^{7}$ http://www.ncdc.noaa.gov/data-access/land-based-station-data/land-based-datasets/globalhistorical-climatology-network-ghcn. 


$$
P_{i t}=\lambda_{1} O_{i t}+\lambda_{2} T_{i t}+X_{i t}^{\prime} \eta_{0}+\tau_{i}+\pi_{t}+\xi_{i t}
$$

where $P_{i t}$ is the air pollution level in city $i$ at time $t, Y_{i t}$ is the health outcome in city $i$ at time $t$, $X_{i t}$ is a set of control variables, $u_{i}$ and $\tau_{i}$ are city fixed effects, $v_{t}$ and $\pi_{t}$ are time fixed effects, and $\varepsilon_{i t}$ and $\xi_{i t}$ are unobservable disturbances. $O_{i t}$ is a regulation status indicator. If city $i$ is regulated at time $t, O_{i t}=1$; otherwise, it is 0 . $T_{i t}$ is the traffic control status indicator. If city $i$ enforces traffic controls during the BOG08, $T_{i t}=1$; otherwise, it is 0 . Both $O_{i t}$ and $T_{i t}$ are instrumental variables that cause changes in air pollution without directly affecting mortality.

As discussed in the previous sections, radical air pollution controls started in November 2007, so we treat this month as the starting month of the regulation period. Some interventions, such as traffic control and temporary emission controls, were abandoned immediately after September 2008, while others, such as some factory shutdowns and relocations, became permanent. Since these regulations might have lasting effects on air quality, we choose December 2008, three months after the Olympics, as the ending point. ${ }^{8}$ Thus, the regulation dummy, $O_{i t}$, takes the value of 1 if a city was regulated due to the BOG08 from November 2007 to December 2008 and 0 otherwise. We also experiment with various ending points and present the results in Section VII.

Beijing and Tianjin faced more stringent regulations than other cities during the Olympics, with both cities enforcing temporary traffic controls during July-September 2008. To capture the treatment intensity differences, we include a traffic control dummy $T_{i t}$ (serving as a

\footnotetext{
${ }^{8}$ Please refer to Section VII for reasons why December 2008 is the appropriate ending point for our empirical analysis.
} 
second instrumental variable), which equals 1 during July-September 2008 for Beijing and Tianjin. ${ }^{9}$ Figure 2 shows the timeline of different regulations.

In the first stage, we use Equation (2) to estimate how the air quality regulations affected air pollution. The coefficient $\lambda_{1}$ is essentially a difference-in-difference estimator, capturing differences in the changes in air pollution levels during regulation periods (November 2007 to December 2008) and non-regulation periods (January 2006 to October 2007, January 2009 to December 2010) between the locations that were regulated and those that were not. $\lambda_{2}$ has a similar interpretation. We expect both $\lambda_{1}$ and $\lambda_{2}$ to be negative. In the second stage of the IV regression, we use the estimate of pollution level $\hat{P}_{i t}$ from the first stage. If air pollution negatively affects people's health, we expect that fewer people will die in the regulated cities than in the unregulated cities during periods of low air pollution and that $\delta_{0}$ will be positive.

Figure 3 shows trends in the monthly average $P M_{10}$ concentrations for both the regulated (9 city-districts) and non-regulated cities (25 city-districts) during 2006-2010. We observe a strong seasonality pattern in the trends of air quality for both treated and control groups, with better air quality in summer than in winter for both groups. In the control group, air quality is relatively stable from year to year. The average $P M_{10}$ concentrations are higher in the treated group than in the control group before 2008. In contrast, air quality improved significantly in 2008 in the treated group. Air quality in 2009 and 2010 for the treated group became slightly worse than in 2008, suggesting that the effects of the regulations on air pollution diminished over time.

\footnotetext{
${ }^{9}$ The point estimate and significance of the effect of air pollution on mortality is essentially unchanged if we use only one instrumental variable, $O_{i t}$. However, using two instrumental variables improves the significance of the first stage of the regression analysis.
} 


\section{Results}

\section{A. The Effects of Air Pollution on Mortality}

Table 2 presents the results from estimating equations (1) and (2) using two-stage least square estimation. The first three columns are estimates from the first stage. In column 1 we estimate the effect of the two instruments (the general comprehensive Olympic air pollution regulation $O_{i t}$ and traffic control $T_{i t}$ ) on $P M_{10}$ concentrations using Equation (2). Columns 2-3 correspond to specifications that include additional controls. We include temperature and precipitation as weather controls because they are typical confounding factors in the associational studies. Air pollution tends to increase on both extremely hot and cold days, due to excessive energy consumption. At the same time, people are more likely to die on both extremely hot and cold days (Deschenes and Moretti 2009). Rain can wash away pollutants in the air, so it is often negatively correlated with air pollution. Rainfall might influence mortality because it changes the humidity and disease environment. All specifications adjust for both city-district fixed effects and year-month fixed effects.

Both general regulations and traffic control are estimated to have strong effects on air pollution and the overall model explains approximately 65 percent of the variations in $\mathrm{PM}_{10}$ concentrations. The estimates for both instrument variables are remarkably stable across all three specifications. ${ }^{10}$ Together, regulating rules and traffic control reduce monthly $P M_{10}$ concentrations by approximately $30 \mu \mathrm{g} / \mathrm{m}^{3}$ or 30 percent in a short period. The results suggest that air quality regulations had a large effect on the air pollution levels.

${ }^{10}$ We also experiment with higher order terms for temperature and precipitation. These specifications appear to have little impact on the estimates. 
The next three columns show the results of air pollution effect on mortality. The control variables, city, and month fixed effects are the same as in the first stage. The dependent variable is the number of deaths per 100,000 people adjusted by standard population structure in China using the 2000 Census. The pollution variable, $\mathrm{PM}_{10}$, is estimated to have strong effects on mortality and are robust to controlling for weather. The estimates are statistically significant at the 5 percent level and imply that a $10-\mu \mathrm{g} / \mathrm{m}^{3}$ decline in monthly $P M_{10}$ concentrations results in 2.35-2.84 fewer deaths per 100,000 people (6.57-7.94 percent reduction relative to its mean). The overall model explains 34-47 percent of the variations in mortality. The results provide causal estimates of the effect of particulate matter pollution on standardized mortality in China's urban areas. In Appendix Table C.1, we find similar results for the API.

As has been documented in the public health and epidemiological literature (Pope, Dockery, and Schwartz 1995), particulate air pollution has heterogeneous impacts on different diseases. Deaths caused by CVR diseases are found to be associated with both short- and longterm exposure to particulate air pollution. In contrast, associations are rarely found between particulate matters and non-CVR mortality. Thus, we estimate the effect of $P M_{10}$ on different causes of mortality. Table 3 presents the estimation results of $P M_{10}$ on CVR mortality, non-CVR mortality, injury mortality, and cancer mortality based on the same specification as in Table 2 . The estimated coefficient of 0.164 in the first column implies that a $10-\mu \mathrm{g} / \mathrm{m}^{3}$ reduction in monthly $P M_{10}$ concentrations leads to 1.64 fewer CVR deaths per 100,000 people per month, or a 10.2 percent drop in the CVR mortality rate. The estimated coefficients of air pollution on nonCVR and cancer mortality in columns (2) and (3) are much smaller and statistically insignificant. In column (4), the estimate for injury mortality is statistically insignificant and close to zero in 
magnitude. The results using the API are consistent with those using $P M_{10}$, as reported in Appendix Table C.2.

\section{B. Validity of Instrumental Variables}

The biggest concern about the identification strategy is that the regulations during the BOG08 might have led to not only air quality improvement, but also changes in other factors influencing human health. For example, it could be that more medical treatments became available in the regulated cities during the BOG08, thus less people died. There also might be positive (negative) regional-specific income shocks causing more (less) people to die. Furthermore, for air pollution regulations to be valid instruments, they must affect mortality only through their effects on air pollution. We address the validity of the instrumental variables in two ways.

First, we check whether the results are robust to the inclusion of typical confounders in air pollution studies. If controlling for other factors changes the estimates, the validity of the instruments would be questionable and the estimates might be biased. Weather conditions are typical confounders in estimating the health effects of air pollution because they change air pollution levels and also affect human health. In cross-sectional and time-series studies, including weather controls will substantially change the air pollution effects. The first-stage results in Table 2 show that the estimated coefficients of the two instruments are statistically significant in all three specifications and including weather controls has little effect on them, which suggests that the two instrumental variables are not correlated with weather conditions. Furthermore, the coefficients of $P M_{10}$ only slightly decrease when the weather controls are included. In other words, these weather control variables are not correlated with variations in air pollution induced by the regulations. In the next section (VII), we also conduct sensitivity analysis to show that the results are still robust when we include regional trends and a set of 
yearly socioeconomic variables. In conclusion, these results show no evidence that air pollution variations induced by regulations are correlated with unobserved potential confounding factors.

Second, we show that the reduced mortality during the BOG08 is likely only caused by the improved air quality rather than other factors. If the Olympic regulations not only improved air quality, but also significantly changed other health-influencing factors, such as availability of medical services, the air-pollution-irrelevant mortality rates during the BOG08 would decrease as well.

Figure 4 depicts the trends of mortality differences between the treatment and control cities over time using locally weighted regression smoothing. The solid line, which shows the CVR mortality differences between the treatment and control cities, was stable in 2006 and early 2007 and started to decrease in late 2007 when the regulations began. It stayed at a low level for more than a year until mid-2009 when a fast rising trend started. This U-shape fitted line is consistent with the natural experiment story that during the regulated period, the regulated cities experienced a larger drop in CVR mortality than the control cities. In contrast, the short dashed line, which depicts the non-CVR mortality differences between the treatment and control cities, does not have a similar pattern. The non-CVR mortality difference followed an increasing trend over the course of five years. Among all the non-CVR causes of death, two categories clearly should not be affected by monthly changes in air pollution: injury and cancer. The long dashed and dotted lines indicate the trends for injury and cancer, respectively. Both lines are stable around -1 , suggesting that the injury mortality and cancer mortality in both groups followed similar trends over time.

Table 4 presents the reduced-form results of regressing mortality rates on air pollution regulations. The estimated coefficients of both the Olympic general air pollution regulation and 
traffic control are negative in the first column, suggesting that fewer people died in the regulated cities during the regulated period than in the unregulated period. We test whether the two instrumental variables are jointly zero, and we can reject the null hypothesis at the 10 percent level for all-cause mortality (column 1) and at the 5 percent level for CVR mortality (column 2). In contrast, we fail to reject the null hypothesis that both instruments are jointly zero for nonCVR mortality, injury mortality, and cancer mortality. The results of the reduced form show that the BOG08 regulations decreased CVR mortality, but not non-CVR mortality, injury mortality, or cancer mortality, in regulated cities. To rule out extreme cases in which the BOG08 might affect injury mortality (for example, traffic controls might reduce car accident deaths), we estimate the same set of specifications excluding the traffic control months. The results are the same.

\section{Robustness Checks}

\section{A. Choices of the End Time}

As we discussed in Section III, there is no official announcement of the end of the air quality regulations. Some regulations, such as traffic control and temporary emission restrictions, were abandoned immediately after the BOG08; while others, such as plant renovation and relocation, may have longer impact on air quality than temporary controls. Therefore, our findings might be sensitive to the end time of the treatment period.

To address this concern, we experiment with eight different end times from September 2008 to April 2009 using the most restrictive specification. Table 5 summarizes the estimates. For the all-cause mortality rate in the first column, the first half of the estimates from September to December 2008 are statistically significant at the 5 percent level and the other half are 
significant at the 10 percent level. For CVR mortality in the second column, all estimates are statistically significant at the 5 percent level. More important, the estimates are remarkably similar across various end times. The estimated coefficients of $P M_{10}$ range from 0.194 to 0.237 for all-cause mortality and from 0.133 to 0.164 for CVR mortality. In our main analysis, we choose December 2008 as the end time for our main specification because (1) the end of the calendar year is often the end of temporary policies; and (2) three months after the BOG08 should be long enough for normal production activities to resume.

\section{B. Ruling Out Temporary Confounding Factors during the BOG08}

A potential threat to our findings is that the effect of air pollution on mortality might be driven by temporary factors during the BOG08. Such factors include increased exposure to outdoor air pollution of spectators during the BOG08, increased incidences of heart attack associated with the excitement of sporting events, more timely medical treatment associated with improved traffic conditions, and greater availability of doctors owing to a reduced number of patients due to restriction on entering the treatment cities during the BOG08 period. The overall bias associated with these factors could be negative or positive.

The BOG08 were held between August $8^{\text {th }}$ and $24^{\text {th }}$. As shown in Figure 3, the largest air quality improvement occurred in July, and air quality peaked in August. To eliminate bias caused by potential confounding factors during the 17-day period, we exclude July and August 2008 from the sample. If dropping these two months has a large impact (either positive or negative) on the estimates of $P M_{10}$, confounding factors correlated with the 17-day period of the BOG08 could potentially bias our results.

The regression results excluding observations of July and August 2008 are reported in the

first panel of Table 6. The first three columns present estimates for all-cause mortality and the 
next three columns are for CVR mortality. The new coefficient estimates for $P M_{10}$ are only slightly smaller than those in Table 2 and Table 3. For all-cause mortality, the estimated coefficients of $P M_{10}$ range from 0.228 to 0.238 and are statistically significant at the 10 percent level. For CVR mortality, the coefficients of $P M_{10}$ are statistically significant at the 5 percent level in all specifications. Thus, excluding data of July and August 2008 has a negligible impact on the effects of air pollution, ruling out the possibility that our findings are due to temporary activities during the BOG08.

\section{Regional Trends}

China is a vast country and health-related conditions vary substantially across regions. The mortality rates and air quality in different regions may, for various reasons, follow different trends. For example, some regions may experience epidemics that lead to extra deaths while others do not; or some regions may experience decreases in mortality rates due to faster economic growth than others. To address these concerns, we control for a set of regional time trends in the model.

We categorize the 34 city-districts into five groups based on the treatment status and the regional economic development according to the Development Research Center of the State Council. These five groups are regulated cities, northeastern cities, coastal cities, inland central cities, and inland western cities. The second panel of Table 6 presents the results with regional trends. The estimated coefficients of $P M_{10}$ are robust across different specifications. In the most restrictive specification, the estimated $P M_{10}$ coefficients are 0.235 and 0.166 for all-cause mortality and CVR mortality, respectively, which are nearly identical to the corresponding estimates in Table 2 and Table 3. This analysis shows that controlling for regional trends has little effect on the point estimates of air pollution. 


\section{Socioeconomic Characteristics}

Given the data constraints, we do not have socioeconomic characteristics measured at the month level. Instead, we include a set of yearly socioeconomic controls to check if our findings are sensitive to the socioeconomic differences between the treatment and control cities. We include per capita GDP, the share of manufacturing production, gross fixed-assets investment per capita, and the number of hospital beds per capita in the regressions. ${ }^{11}$ Per capita GDP and gross fixedassets investment per capita capture mortality differences across cities due to different economic conditions. The share of manufacturing production represents the economic structure of the local economy. The number of hospital beds per capita serves as a measure of the availability of local medical resources. Socioeconomics characteristics are missing for several control cities. As a consequence, the sample size of the robustness check decreases to 1,824 from 1,932.

Results are presented in the third panel of Table 6. We find that the estimated coefficients of $P M_{10}$ are slightly smaller when we control for socioeconomic characteristics. They are statistically significant at the 5 percent level for overall mortality and at the 10 percent level for CVR mortality. The smaller coefficients of air pollution might be caused by the sample difference. This analysis shows that air pollution effects are still robust even after controlling for important socioeconomic factors that would mitigate the health effect of a non-random change in air pollution. We conclude that air pollution variations induced by regulations are also unlikely to be correlated with other potential unobserved confounding factors.

\footnotetext{
${ }^{11}$ The socioeconomic variables are collected by authors from China's City Statistical Yearbooks from 2006 to 2010.
} 


\section{Comparison with Estimates from Associational Models}

\section{A. Cross-sectional Models and Fixed-Effects Models}

In this section we compare our results with those in associational studies. The major concern in estimating the health effects of air pollution in the cross-sectional and panel (fixed-effects) models is that air pollution may be correlated with various omitted variables.

A cross-sectional model can be written as:

$$
Y_{i t}=\delta_{0} P_{i t}+X_{i t}^{\prime} \eta_{0}+u_{i t}, u_{i t}=v_{i}+\varepsilon_{i t}
$$

The effect of air pollution on health outcomes is captured by $\delta_{0}$ if air pollution is uncorrelated with the unobserved disturbance, $E\left[P_{i t} u_{i t}\right]=0$. However, as air quality is not randomly assigned across locations, this condition may not hold. For example, if air pollution is positively associated with other types of unobserved pollution (e.g., water pollution or hazardous waste), the estimates will be biased upward. However, if polluted areas are relatively wealthy and have superior medical and sanitation facilities, the cross-sectional estimates will be biased downward.

We replicate the conventional cross-sectional approach to estimating the association between $P M_{10}$ pollution and mortality separately for each year, using three different specifications with different sets of weather controls. We then stack five years of data and estimate a pooled OLS regression model.

The regression results are reported in Table 7. In the specification without weather control variables (the first column), the estimated effects of $P M_{10}$ vary widely across the years. The estimates vary from an insignificant 0.007 in 2006 to a significant 0.038 in 2010 . And none of the estimated coefficients is statistically significant except for the 2010 sample. Columns (2) and (3) present the results from specifications that include temperature and precipitation. 
Controlling for weather conditions has a large impact on the estimates. When precipitation and temperature are controlled for, the coefficients of air pollution variables become negative and statistically significant except for the 2010 sample. The results are very sensitive to the year analyzed and the set of variables used as controls, suggesting that the omitted variables may play an important role in cross-sectional models.

Fixed-effects models remove bias from time-invariant factors and are useful when timeinvariant factors explain most of the variations in an outcome variable. However, if changes in air pollution are correlated with changes in other unobserved factors (such as temperature, humidity, and other pollutants) that also affect health outcomes, the fixed-effects estimates will be biased as well.

In a fixed-effects model, we estimate:

$$
Y_{i t}-\bar{Y}_{i}=\delta_{0}\left(P_{i t}-\bar{P}_{i}\right)+\left(X_{i t}^{\prime}-\bar{X}_{i}^{\prime}\right) \eta_{0}+\varepsilon_{i t}
$$

where $\bar{Y}_{i}=\sum_{t=1}^{T} Y_{i t} / T, \bar{P}_{i}=\sum_{t=1}^{T} P_{i t} / T$, and $\bar{X}_{i}=\sum_{t=1}^{T} X_{i t} / T$.

Table 8 summarizes the regression results for the fixed-effects model. In the first column, we only control for city fixed effects, and the effect of air pollution is positively and statistically significantly associated with a higher mortality rate at the 1 percent level. When we also include weather variables (the second column), the estimated coefficients decrease by more than twothirds and become statistically insignificant. That is, including the weather variables in the city fixed-effects model still substantially affects the estimated effects of air pollution. We control for year-month fixed effects other than city fixed effects in the third column. The estimated air pollution effect becomes insignificant at the conventional level and close to zero in magnitude. However, when we control for both weather and year-month fixed effects, the estimated coefficient becomes statistically significant, but the magnitude decreases by more than 70 
percent compared with the first column. The estimates for CVR mortality follow a similar pattern. The results suggest that air pollution variations are correlated with fluctuations in weather conditions which may affect mortality directly or through channels other than air pollution.

As such, we conclude that the variations in air pollution over time and across regions cannot be treated as exogenous, even after controlling for city fixed effects and year-month fixed effects. Because other unobserved variables (such as wind) may co-vary with both air pollution and mortality rates, estimates of fixed-effects models may also be biased.

\section{B. Comparison with Previous Studies}

In this subsection, we compare our estimates with previous studies. One should be careful when comparing the estimates across different studies since there are numerous differences between the research designs and settings. Still, these studies share many similarities and some of the differences are noteworthy.

Most contemporary research of air pollution's health effects uses either time-series or cohort approaches. Time-series studies assess the short-term relationships between exposure to pollution and adverse health outcomes. Such studies often adopt generalized linear or generalized additive models to estimate the health effects of air pollution, using daily death and air pollution data. Among the voluminous time-series studies, we compare our results with those

in two influential multi-site time-series studies: the Air Pollution and Health: A European Approach (APHEA) project, and the National Morbidity, Mortality and Air Pollution Study (NMMAPS).

The APHEA project, supported by the European Commission, studied the short-term effects of air pollution on human health in 12 European cities (Katsouyanni et al. 1997). APHEA 
researchers estimated that a $10-\mu \mathrm{g} / \mathrm{m}^{3}$ increase in daily $P M_{10}$ was associated with a 0.4 percent increase in total daily mortality for western European cities and a 0.8 percent increase in total daily mortality for central eastern European cities. Katsouyanni et al. (2001), the follow-up APHEA2 project, examined mortality and pollution in 29 European cities and found that a 10$\mu \mathrm{g} / \mathrm{m}^{3}$ increase in daily $P M_{10}$ was associated with a 0.6 percent increase in total daily mortality. The NMMAPS examined the effect of $P M_{10}$ on mortality in U.S. cities (Samet et al. 2000). The NMMAPS research team first investigated 20 large U.S. cities; then extended their analysis to 90 large U.S. cities. The results showed that a $10-\mu \mathrm{g} / \mathrm{m}^{3}$ increase in daily $P M_{10}$ was associated with a 0.21 percent increase in all-cause mortality, and a 0.31 percent increase in CVR mortality.

Cohort studies assess the association between air pollution and mortality using data with a much longer time scale. Substantially larger health effects of air pollution have been reported in the long-term cohort studies than in the high-frequency time-series studies. ${ }^{12}$ The first large cohort study that demonstrated an adverse health impact of long-term air pollution exposure was the Harvard Six Cities study by Dockery et al. (1993). In a cohort of 8,111 adults, with 14 to 16 years of follow-up, the authors found that the adjusted ratio of the mortality rate of the mostpolluted city to that of the least-polluted city was 1.26 , with cardiovascular deaths accounting for the single largest category of difference in mortality. The relative risks in all-cause mortality were associated with a difference in ambient fine particles concentrations: a $10-\mu \mathrm{g} / \mathrm{m}^{3}$ difference in $P M_{2.5}$ concentrations was associated with an approximately 14 percent difference in the all-cause mortality rate.

\footnotetext{
${ }^{12}$ For example, Schwartz (2000) shows that, as data become more aggregated, the effects of air pollution on ischemic heart disease mortality and all-death mortality increase, suggesting larger effects of long-term exposure, possibly due to development of chronic diseases.
} 
Pope et al. (2002) conducted another large prospective cohort study of the long-term health effects of air pollution, using data from the American Cancer Society Cancer Prevention II project. Among approximately 500,000 adults in 50 states in the United States, chronic exposure to multiple air pollutants was linked to mortality statistics over a 16-year window. They showed that a $10-\mu \mathrm{g} / \mathrm{m}^{3}$ increase in the annual mean concentrations of fine particulate matter $\left(P M_{2.5}\right)$ was associated with increases in all-cause, cardiopulmonary, and lung cancer mortality of 4 percent, 6 percent, and 8 percent, respectively. Pope et al. (2004) further examined the association between air pollution and specific cardiopulmonary diseases to explore potential mechanistic pathways linking exposure to mortality. They found that long-term particulate matter exposure was most strongly associated with mortality attributable to ischemic heart disease, dysrhythmias, heart failure, and cardiac arrest. For these causes of death, a $10-\mu g / \mathrm{m}^{3}$ elevation in $P M_{2.5}$ was associated with an 8 to 18 percent increase in mortality risks, with greater risk observed for smokers than nonsmokers.

Our results in the most restrictive specification show that a $10-\mu \mathrm{g} / \mathrm{m}^{3}$ change in monthly average $P M_{10}$ concentrations would lead to a 6.63 percent change in all-cause mortality, and 10.2 percent change in CVR mortality. In Beijing and many other Chinese cities, $P M_{2.5}$ usually accounts for 50-70 percent of $P M_{10}$ (Yu et al. 2004, Yang et al. 2002). If we use 60 percent for a crude calculation, a $10-\mu \mathrm{g} / \mathrm{m}^{3}$ elevation in monthly $P M_{2.5}$ concentrations would roughly lead to an 11 percent increase in monthly standardized mortality, and an 18 percent increase in CVR mortality. Therefore, the estimated health effects of air pollution in this study are comparable to those from the cohort studies and are much larger than those from time-series studies.

\section{Health Benefit of Air Pollution Reduction}


As is pointed out in Dominici, Greenstone, and Sunstein (2014), a critical question particulate matter research is to identify the magnitude of public health benefits from reduction of particulate matters. We assess the benefits of improving China's air quality and provide a range of estimates on the monetary value of the averted deaths in this section. The improved air quality during the BOG08 brought about significant health benefits in the treatment cities. Policies aiming to reduce air pollution can have large benefits in terms of population health and life expectancy. According to the 2010 Census, China has 690 million urban inhabitants. Based on our estimates in column (6) of Table 2, more than 196,000 $(12 * 2.37 * 690,000,000 / 100,000)$ deaths per year could be avoided among China's urban population in one year if $P M_{10}$ concentrations were to decrease by $10 \mu \mathrm{g} / \mathrm{m}^{3}$.

The WHO (2005) sets an annual mean of $20 \mu \mathrm{g} / \mathrm{m}^{3}$ as the guideline for $P M_{10}$ concentration based on a summary of risk assessments. If we assume that the dose-response function is linear, then at the current air pollution level (about $100 \mathrm{\mu g} / \mathrm{m}^{3}$ ), a back of envelope calculation shows that about 1.57 million $(12 * 0.237 * 80 * 690,000,000 / 100,000)$ pre-mature deaths in urban China can be attributed to air pollution. It is of great policy interest to estimate the economic value of the health benefits associated with improved air quality. A comprehensive evaluation of the health benefits of air pollution requires measurements of a variety of health outcomes, such as mortality, incidence of chronic bronchitis, respiratory and cardiovascular hospital admission, work loss days, and worker productivity. Among all these outcomes, averted premature deaths are associated with the highest economic value. The mortality risks are typically valued using the value of a statistical life (VSL) — the amount of money that people would pay to reduce their risk of dying. The VSL is often estimated from contingent valuation surveys or through the hedonic wage approach. 
Several studies have been conducted in China to value the mortality risk reduction. We focus on five most recent studies published after 2006. Among them, three use the contingent valuation approach and the other two use the hedonic wage approach. The VSL estimates in these studies are summarized in Table 9. The estimated VSL in China ranges from 0.24 to 3.84 million Yuan, depending on when and where the data were collected and which approach was used. We calculate the monetary value of averted pre-mature deaths by multiplying the VSL by the number of predicted lives saved $(196,236)$ for the urban population associated with a 10 $\mu g / m^{3} P M_{10}$ reduction and report the results in column (4) of Table 6. The estimated benefits range from 47.1 to 753.9 billion Yuan. The World Bank (2007) uses 1 million Yuan as a conservative VSL estimate in China. If we use the same value as the World Bank (2007), a benefit of approximately 200 billion Yuan would be derived from reducing the current $P M_{10}$ concentrations by $10 \mu \mathrm{g} / \mathrm{m}^{3}$ (a roughly 10 percent decrease).

The VSL also allows us to calculate the health benefits associated with a higher pollution abatement. In column (5), we calculate the benefits if the $P M_{10}$ concentrations decrease to the WHO guideline level from the current level (about $100 \mu \mathrm{g} / \mathrm{m}^{3}$ ). The lowest benefit associated with the abatement is approximately 380 billion Yuan, and the highest benefit is more than 6 trillion Yuan. If the VSL of an averted pre-mature death is set at 1 million Yuan, the total health benefits will exceed 1,570 billion Yuan, this amounts to 5 percent of Chinese GDP for 2008. The values in column (5) are likely to be the lower bounds of potential benefits from air pollution abatement and should be interpreted with caution because (1) evidence from studies in China and Western countries shows that the exposure-response relationship may become less steep as particulate pollution levels increase (Almond et al. 2009, Samoli et al. 2001), and (2) they ignore 
any health episodes that do not result in deaths such as hospitalizations and other direct effects on well-being unrelated to sickness or death.

All the locations in this study are urban districts, so the economic valuation in Table 9 are based solely on the urban population. The health effects of air pollution for the rural population may be different. Rural residents are less likely to adopt certain avoidance behaviors, such as wearing masks or installing air filters, in response to air pollution attacks. They may also be more vulnerable to air quality shocks because their ex ante health status is worse than that of urban residents; consequently the impact of air pollution on health may be greater for rural residents than for urban residents. There is some evidence supporting this proposition. For example, Zhou et al. (2015) find that the smog episodes are associated with higher mortality in rural areas than in urban areas. Future studies are warranted to evaluate the differential health benefits in China's urban and rural populations.

\section{Conclusions}

This study investigates the causal link between air pollution and mortality in China, using the BOG08 as a quasi-natural experiment. We find that air pollution has a large and robust effect on mortality. Our results show that a $10-\mu \mathrm{g} / \mathrm{m}^{3}$ decrease in $P M_{10}$ concentrations results in 2.37 fewer deaths per 100,000 people per month (a 6.63 percent drop). Based on our estimates and China's urban population, more than 196,000 premature deaths can be averted each year if the current level of $P M_{10}$ concentrations were reduced by $10 \mu \mathrm{g} / \mathrm{m}^{3}$.

Our analysis also shows that the effects of air pollution are driven by fewer deaths from cardio-cerebrovascular and respiratory diseases. We find that a $10-\mu \mathrm{g} / \mathrm{m}^{3}$ reduction decreases

monthly CVR mortality by 10.2 percent. Since people who have no pre-existing cardiac 
conditions have also been found to contract certain cardiac diseases (particularly cardiac arrests) resulting in death, the effect of air pollution is likely to be large in terms of the loss of qualityadjusted life years.

We rule out the possibility that temporary activities during the BOG08, such as migration, increased incidences of heart attack associated with the excitement of sporting events, more timely medical treatment associated with improved traffic conditions, or other factors related to the BOG08, might confound our estimates by dropping the data of July and August 2008. In addition, we conduct falsification tests and find that air pollution does not affect mortalities from diseases that are not related to air pollution, in particular injury and cancer mortalities. We can also rule out the "harvesting" effect because we use monthly data and the treatment period is longer than a year. All these results indicate that the relationship between air pollution and mortality is likely to be causal.

In contrast, estimates from cross-sectional and fixed-effects models are sensitive to weather controls and model specifications. Estimates from associational models are substantially smaller, indicating that they may underestimate the health effects of air pollution. Our estimates are much larger than those in time-series studies. This finding is in keeping with Schlenker and Walker (2011), who also find that estimates of air pollution effects obtained using a natural experiment design were much larger than estimates obtained through non-experimental approaches.

We are aware of two caveats in this study that call for cautious interpretation of our results. First, our results might be locally valid only and cannot be generalized to the lower level of air pollution because the effects of air pollution on health might be non-linear and perhaps negligible below a certain threshold. We also caution readers not to generalize our results to 
China's rural areas which are dramatically different from cities. Second, people’s behavioral changes during the study period are not examined due to lack of data. An individual's level of pollution exposure is determined by outdoor air quality, indoor air quality and how one divides one's time between indoor and outdoor activities. People may adjust their behaviors in response to changes in air pollution. In particular, those at risk of being negatively affected by pollution may have relatively strong incentives to adopt avoidance behaviors. For example, Neidell (2009) find that people respond to information about air quality, with smog alerts leading to significantly reduced attendance at major outdoor facilities in Los Angeles. Thus, the BOG08 may have affected people's preferences between indoor and outdoor activities. The consequences of such behavioral changes on mortality merit further investigation. 


\section{REFERENCES}

Almond, Douglas, Yuyu Chen, Michael Greenstone, and Hongbin Li. 2009. "Winter Heating or Clean Air? Unintended Impacts of China's Huai River Policy." The American Economic Review 99 (2):184-190.

Arceo-Gomez, Eva O, Rema Hanna, and Paulina Oliva. 2012. Does the effect of pollution on infant mortality differ between developing and developed countries? Evidence from Mexico City. NBER Working Paper No. 18349.

Bell, Michelle L., Jonathan M. Samet, and Francesca Dominici. 2004. "Time-Series Studies of Particulate Matter." Annual Review of Public Health 25 (1):247-280. doi: doi:10.1146/annurev.publhealth.25.102802.124329.

Chay, Kenneth, Carlos Dobkin, and Michael Greenstone. 2003. "The Clean Air Act of 1970 and adult mortality." Journal of Risk and Uncertainty 27 (3):279-300.

Chay, Kenneth Y, and Michael Greenstone. 2003a. Air quality, infant mortality, and the Clean Air Act of 1970. NBER Working Paper No. 10053.

Chay, Kenneth Y, and Michael Greenstone. 2003b. "The impact of air pollution on infant mortality: evidence from geographic variation in pollution shocks induced by a recession." The Quarterly Journal of Economics 118 (3):1121-1167.

Chen, Yuyu, Avraham Ebenstein, Michael Greenstone, and Hongbin Li. 2013. "Evidence on the impact of sustained exposure to air pollution on life expectancy from China's Huai River policy." Proceedings of the National Academy of Sciences 110 (32):12936-12941. doi: 10.1073/pnas.1300018110.

Chen, Yuyu, Ginger Zhe Jin, Naresh Kumar, and Guang Shi. 2013. "The promise of Beijing: Evaluating the impact of the 2008 Olympic Games on air quality." Journal of Environmental Economics and Management 66 (3):424-443. doi: http://dx.doi.org/10.1016/j.jeem.2013.06.005.

Chen, Yuyu, Jin Ginger Zhe, Kumar Naresh, and Shi Guang. 2012. "Gaming in Air Pollution Data? Lessons from China." The BE Journal of Economic Analysis \& Policy 13 (3):1-43.

Currie, Janet, and Matthew Neidell. 2005. "Air pollution and infant health: What can we learn from California's recent experience?" The Quarterly Journal of Economics 120 (3):10031030.

Currie, Janet, Matthew Neidell, and Johannes F Schmieder. 2009. "Air pollution and infant health: Lessons from New Jersey." Journal of Health Economics 28 (3):688-703.

Deschenes, Olivier, and Enrico Moretti. 2009. "Extreme weather events, mortality, and migration." The Review of Economics and Statistics 91 (4):659-681.

Dockery, Douglas W, C Arden Pope, Xiping Xu, John D Spengler, James H Ware, Martha E Fay, Benjamin G Ferris Jr, and Frank E Speizer. 1993. "An association between air pollution and mortality in six US cities." New England Journal of Medicine 329 (24):1753-1759.

Dominici, Francesca, Michael Greenstone, and Cass R. Sunstein. 2014. "Particulate Matter Matters." Science 344 (6181):257-259. doi: 10.1126/science.1247348.

Graff Zivin, Joshua, and Matthew Neidell. 2009. "Days of haze: Environmental information disclosure and intertemporal avoidance behavior." Journal of Environmental Economics and Management 58 (2):119-128. doi: http://dx.doi.org/10.1016/j.jeem.2009.03.001.

Greenstone, Michael, and Rema Hanna. forthcoming. "Environmental regulations, air and water pollution, and infant mortality in India." American Economic Review. 
Guo, Xiaoqi, and JamesK Hammitt. 2009. "Compensating Wage Differentials with Unemployment: Evidence from China." Environmental and Resource Economics 42 (2):187-209. doi: 10.1007/s10640-008-9217-9.

Hammitt, JamesK, and Ying Zhou. 2006. "The Economic Value of Air-Pollution-Related Health Risks in China: A Contingent Valuation Study." Environmental and Resource Economics 33 (3):399-423. doi: 10.1007/s10640-005-3606-0.

Jayachandran, Seema. 2009. "Air quality and early-life mortality evidence from Indonesia's wildfires." Journal of Human Resources 44 (4):916-954.

Kassebaum, Nicholas J., Amelia Bertozzi-Villa, Megan S. Coggeshall, et al. 2014. "Global, regional, and national levels and causes of maternal mortality during 1990?2013: a systematic analysis for the Global Burden of Disease Study 2013." The Lancet.

Katsouyanni, Klea, Giota Touloumi, Evangelia Samoli, et al. "Confounding and Effect Modification in the Short-Term Effects of Ambient Particles on Total Mortality: Results from 29 European Cities within the APHEA2 Project." Epidemiology 12 (5):521-531. doi: $10.2307 / 3703877$.

Katsouyanni, Klea, Giotta Touloumi, Claudia Spix, et al. 1997. "Short-term effects of ambient sulphur dioxide and particulate matter on mortality in 12 European cities: results from time series data from the APHEA project. Air Pollution and Health: a European Approach." BMJ: British Medical Journal 314 (7095):1658-1663.

Krupnick, Alan, Sandra Hoffmann, Bjorn Larsen, Xizhe Peng, Ran Tao, Chen Yan, and Michael McWilliams. 2006. "The willingness to pay for mortality risk reductions in Shanghai and Chongqing, China." Resources for the Future, The World Bank: Washington, DC.

Logan, WPD. 1953. "Mortality in the London fog incident, 1952." The Lancet 261 (6755):336338.

Luechinger, Simon. 2010.

Moretti, Enrico, and Matthew Neidell. 2011. "Pollution, health, and avoidance behavior evidence from the ports of Los Angeles." Journal of human Resources 46 (1):154-175.

Neidell, Matthew. 2009. "Information, Avoidance behavior, and health the effect of ozone on asthma hospitalizations." Journal of Human Resources 44 (2):450-478.

OECD. 2012. OECD Environmental Outlook to 2050: OECD Publishing.

Pope, C Arden, Richard T Burnett, Michael J Thun, Eugenia E Calle, Daniel Krewski, Kazuhiko Ito, and George D Thurston. 2002. "Lung cancer, cardiopulmonary mortality, and longterm exposure to fine particulate air pollution." JAMA: the Journal of the American Medical Association 287 (9):1132-1141.

Pope, C Arden, Richard T Burnett, George D Thurston, Michael J Thun, Eugenia E Calle, Daniel Krewski, and John J Godleski. 2004. "Cardiovascular Mortality and Long-Term Exposure to Particulate Air Pollution Epidemiological Evidence of General Pathophysiological Pathways of Disease." Circulation 109 (1):71-77.

Pope, C. Arden, Douglas W. Dockery, and Joel Schwartz. 1995. "Review of Epidemiological Evidence of Health Effects of Particulate Air Pollution." Inhalation Toxicology 7 (1):118. doi: doi:10.3109/08958379509014267.

Qin, Xuezheng, Lixing Li, and Yangyang Liu. 2013. "The value of life and its regional difference in China." China Agricultural Economic Review 5 (3):373-390. doi: doi:10.1108/CAER-06-2011-0065.

Rich, David Q, Howard M Kipen, Wei Huang, Guangfa Wang, Yuedan Wang, Ping Zhu, Pamela Ohman-Strickland, Min Hu, Claire Philipp, and Scott R Diehl. 2012. "Association 
between changes in air pollution levels during the Beijing Olympics and biomarkers of inflammation and thrombosis in healthy young adults." JAMA: the Journal of the American Medical Association 307 (19):2068-2078.

Samet, Jonathan M., Francesca Dominici, Frank C. Curriero, Ivan Coursac, and Scott L. Zeger. 2000. "Fine Particulate Air Pollution and Mortality in 20 U.S. Cities, 1987-1994." New England Journal of Medicine 343 (24):1742-1749. doi: doi:10.1056/NEJM200012143432401.

Samoli, Evangelia, Joel Schwartz, Bogdan Wojtyniak, Giota Touloumi, Claudia Spix, Frank Balducci, Sylvia Medina, Giuseppe Rossi, Jordi Sunyer, and Ljuba Bacharova. 2001. "Investigating regional differences in short-term effects of air pollution on daily mortality in the APHEA project: a sensitivity analysis for controlling long-term trends and seasonality." Environmental health perspectives 109 (4):349-353.

Schlenker, Wolfram, and W Reed Walker. 2011. Airports, air pollution, and contemporaneous health. National Bureau of Economic Research.

Schwartz, Joel. 2000. "Harvesting and long term exposure effects in the relation between air pollution and mortality." American Journal of Epidemiology 151 (5):440-448.

United Nations Environment Programme. 2009. "Independent Environmental Assessment: Beijing 2008 Olympic Games." http://www.unep.org/pdf/BEIJING_REPORT_COMPLETE.pdf.

Wang, Hong, and John Mullahy. 2006. "Willingness to pay for reducing fatal risk by improving air quality: A contingent valuation study in Chongqing, China." Science of The Total Environment 367 (1):50-57. doi: http://dx.doi.org/10.1016/j.scitotenv.2006.02.049.

Wansbeek, Tom J, and Erik Meijer. 2000. Measurement error and latent variables in econometrics. Vol. 37: Elsevier Amsterdam.

World Bank. 2007. Cost of pollution in China : economic estimates of physical damages. Washington, DC: World Bank.

Yang, Fumo, Kebin He, Yongliang Ma, Qiang Zhang, and Xuechun Yu. 2002. "Variation characteristics of $\mathrm{PM}_{2.5}$ concentration and its relationship with PM 10 and TSP in Beijing." China Environmental Science 22 (6):506-510.

Yu, Jianhua, Tong Yu, Qiang Wei, Xin Wang, Jiangang Shi, and Haijun Li. 2004. "Characteristics of Mass Concentration Variations of $\mathrm{PM}_{10}$ and $\mathrm{PM}_{2.5}$ in Beijing Area." Research of Environmental Sciences 17 (1):45-47.

Zhou, Maigeng, Guojun He, Maoyong Fan, Zhaoxi Wang, Yang Liu, Jing Ma, Zongwei Ma, Jiangmei Liu, Yunning Liu, Linhong Wang, and Yuanli Liu. 2015. "Smog episodes, fine particulate pollution and mortality in China." Environmental Research 136 (0):396-404. doi: http://dx.doi.org/10.1016/j.envres.2014.09.038. 
Table 1. Summary Statistics of the Main Variables

\begin{tabular}{lcccc}
\hline \hline & Mean & Std. Dev. & Min & Max \\
\hline $\mathrm{PM}_{10}(\mu \mathrm{g} / \mathrm{m} 3)$ & 98.017 & 38.555 & 26.516 & 386.987 \\
Monthly Standardized Mortality (per 100,000) & 35.750 & 13.722 & 2.328 & 117.740 \\
Monthly Standardized CVR Mortality (per & 16.106 & 7.625 & 0.412 & 60.509 \\
$100,000)$ & & & & \\
Precipitation $(100 \mathrm{~mm})$ & 75.869 & 83.771 & 0.000 & 809.918 \\
Temperature $\left({ }^{\circ} \mathrm{C}\right)$ & 13.499 & 11.102 & -20.298 & 30.885 \\
\hline
\end{tabular}


Table 2. The Effect of $\mathbf{P M}_{10}$ on Mortality

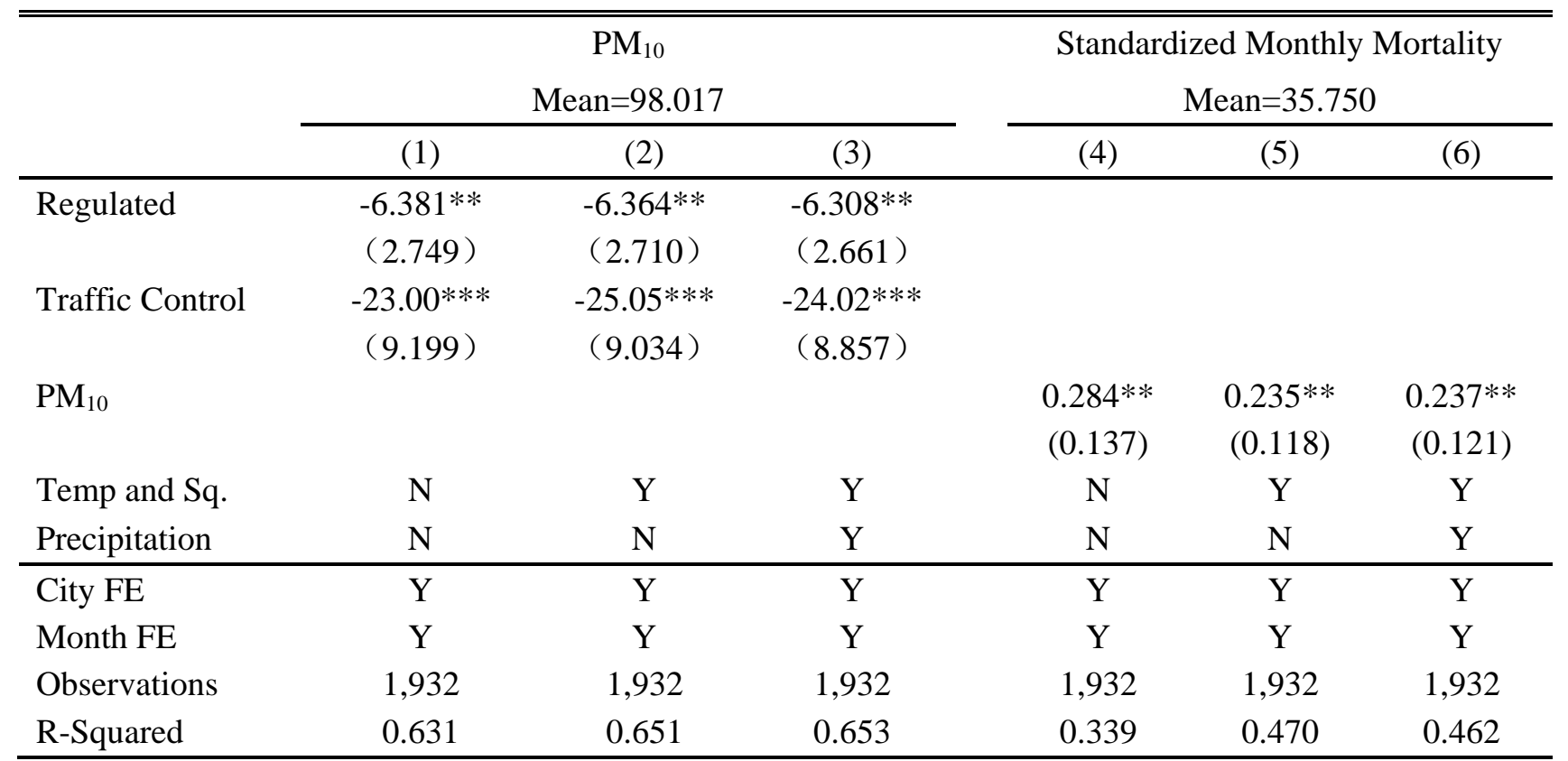

Notes: Standard errors are in parentheses and clustered at the city level. Asterisks, ${ }^{* * *},{ }^{* *}$ and ${ }^{*}$, indicate the $1 \%, 5 \%$ and $10 \%$ significance levels, respectively. 
Table 3. The Effect of $\mathbf{P M}_{10}$ on Disease-Specific Mortalities

\begin{tabular}{lcccc}
\hline \hline & \multicolumn{4}{c}{ Standardized Monthly Mortality (per 100,000 people) } \\
\cline { 2 - 5 } & $\begin{array}{l}\text { CVR } \\
\text { Mean=16.106 }\end{array}$ & Non-CVR & Cancer & Injury \\
& Mean=19.644 & Mean=9.067 & Mean $=2.534$ \\
& $0.164^{* *}$ & $(2)$ & 0.048 & $(4)$ \\
\hline PM $_{10}$ & $(0.076)$ & $(0.072)$ & $(0.031)$ & -0.008 \\
& $\mathrm{Y}$ & $\mathrm{Y}$ & $\mathrm{Y}$ & $(0.013)$ \\
\hline Weather & $\mathrm{Y}$ & $\mathrm{Y}$ & $\mathrm{Y}$ & $\mathrm{Y}$ \\
City FE & $\mathrm{Y}$ & $\mathrm{Y}$ & $\mathrm{Y}$ \\
Month FE & & &
\end{tabular}


Table 4. Reduced Form: The Effect of Air Pollution Regulations on Mortality Rates

\begin{tabular}{lccccc}
\hline \hline & Mortality & CVR & Non-CVR & Injury & \multicolumn{2}{c}{ Cancer } \\
\cline { 2 - 6 } & $(1)$ & $(2)$ & $(3)$ & $(4)$ & $(5)$ \\
\hline Regulated (O) & -3.000 & -1.994 & -1.006 & 0.140 & -0.732 \\
& $(2.012)$ & $(1.180)$ & $(1.149)$ & $(0.202)$ & $(0.480)$ \\
Traffic Control (T) & -1.777 & -1.451 & -0.326 & -0.057 & -0.044 \\
& $(1.952)$ & $(1.295)$ & $(1.077)$ & $(0.221)$ & $(0.546)$ \\
F-Stat. (Ho $\mathrm{H}_{0}$ O=TC=0) & $2.49^{*}$ & $3.83^{* *}$ & 0.45 & 0.25 & 1.3 \\
\hline Weather & $\mathrm{Y}$ & $\mathrm{Y}$ & $\mathrm{Y}$ & $\mathrm{Y}$ & $\mathrm{Y}$ \\
City FE & $\mathrm{Y}$ & $\mathrm{Y}$ & $\mathrm{Y}$ & $\mathrm{Y}$ & $\mathrm{Y}$ \\
Month FE & $\mathrm{Y}$ & $\mathrm{Y}$ & $\mathrm{Y}$ & $\mathrm{Y}$ & $\mathrm{Y}$ \\
\hline
\end{tabular}

Notes: Standard errors are in parentheses and clustered at the city level. Asterisks, ***, ** and *, indicate the $1 \%, 5 \%$ and $10 \%$ significance levels, respectively. 
Table 5. Robustness Check I: Choices of Different End Times

\begin{tabular}{ccc}
\hline \hline & \multicolumn{2}{c}{ PM $_{10}$ Coefficients } \\
\cline { 2 - 3 } & $\begin{array}{c}\text { Mortality } \\
(1)\end{array}$ & CVR Mortality \\
\cline { 1 - 2 } Different End Times of the Treatment Period & & \\
\hline September of 2008 & $0.194^{* *}$ & $0.133^{* *}$ \\
October of 2008 & $(0.091)$ & $(0.063)$ \\
November of 2008 & $0.212^{* *}$ & $0.143^{* *}$ \\
December of 2008 & $(0.102)$ & $(0.067)$ \\
January of 2009 & $0.224^{* *}$ & $0.153^{* *}$ \\
February of 2009 & $(0.111)$ & $(0.072)$ \\
March of 2009 & $\mathbf{0 . 2 3 7 * *}$ & $\mathbf{0 . 1 6 4 * *}$ \\
& $\mathbf{( 0 . 1 2 1 )}$ & $\mathbf{( 0 . 0 7 6 )}$ \\
April of 2009 & $0.226^{*}$ & $0.159^{* *}$ \\
& $(0.119)$ & $(0.074)$ \\
& $0.219^{*}$ & $0.162^{* *}$ \\
& $(0.118)$ & $(0.072)$ \\
& $0.219^{*}$ & $0.164^{* *}$ \\
& $(0.116)$ & $(0.068)$ \\
& $0.203^{*}$ & $0.151^{* *}$ \\
& $(0.110)$ & $(0.061)$ \\
\hline
\end{tabular}

Notes: Weather controls, city-district fixed-effects and year-month fixed-effects are included in all regressions. Standard errors are in parentheses and clustered at the city level. Asterisks, ***, ** and *, indicate the $1 \%, 5 \%$ and $10 \%$ significance levels, respectively. 
Table 6. Robustness Check II: $\mathbf{P M}_{10}$ and Mortality

\begin{tabular}{|c|c|c|c|c|c|c|}
\hline & \multicolumn{3}{|c|}{ Mortality } & \multicolumn{3}{|c|}{ CVR Mortality } \\
\hline & $(1)$ & $(2)$ & $(3)$ & $(4)$ & $(5)$ & $(6)$ \\
\hline \multicolumn{7}{|c|}{ A. Eliminating the game period-July and August of 2008} \\
\hline \multirow[t]{2}{*}{$\mathrm{PM}_{10}$} & $0.238 *$ & $0.228 *$ & $0.232 *$ & $0.162 * *$ & $0.157 * *$ & $0.161^{* *}$ \\
\hline & $(0.134)$ & $(0.129)$ & $(0.134)$ & $(0.078)$ & $(0.077)$ & $(0.081)$ \\
\hline Observations & 1,862 & 1,862 & 1,862 & 1,862 & 1,862 & 1,862 \\
\hline R-Squared & 0.541 & 0.578 & 0.573 & 0.454 & 0.492 & 0.481 \\
\hline \multicolumn{7}{|c|}{ B. Controlling for Regional Trends } \\
\hline \multirow[t]{2}{*}{$\mathrm{PM}_{10}$} & $0.289 *$ & $0.233^{*}$ & $0.235^{*}$ & $0.196 * *$ & $0.163 * *$ & $0.166^{* *}$ \\
\hline & $(0.148)$ & $(0.124)$ & $(0.126)$ & $(0.093)$ & $(0.080)$ & $(0.082)$ \\
\hline Observations & 1,932 & 1,932 & 1,932 & 1,932 & 1,932 & 1,932 \\
\hline R-Squared & 0.471 & 0.576 & 0.574 & 0.362 & 0.491 & 0.484 \\
\hline \multicolumn{7}{|c|}{ C. Controlling for Yearly Socioeconomic Characteristics } \\
\hline \multirow[t]{2}{*}{$\mathrm{PM}_{10}$} & $0.245^{* *}$ & $0.207 * *$ & $0.207 * *$ & $0.146 *$ & $0.123^{*}$ & $0.123 *$ \\
\hline & $(0.114)$ & $(0.098)$ & $(0.102)$ & $(0.075)$ & $(0.065)$ & $(0.067)$ \\
\hline Observations & 1,824 & 1,824 & 1,824 & 1,824 & 1,824 & 1,824 \\
\hline R-Squared & 0.340 & 0.452 & 0.452 & 0.505 & 0.588 & 0.587 \\
\hline $\begin{array}{l}\text { Temp. and its } \\
\text { Square }\end{array}$ & $\mathrm{N}$ & $\mathrm{Y}$ & $\mathrm{Y}$ & $\mathrm{N}$ & $\mathrm{Y}$ & $\mathrm{Y}$ \\
\hline Precipitation & $\mathrm{N}$ & $\mathrm{N}$ & $\mathrm{Y}$ & $\mathrm{N}$ & $\mathrm{N}$ & $\mathrm{Y}$ \\
\hline City FE & $\mathrm{Y}$ & $\mathrm{Y}$ & $\mathrm{Y}$ & $\mathrm{Y}$ & $\mathrm{Y}$ & $\mathrm{Y}$ \\
\hline Month FE & $\mathrm{Y}$ & $\mathrm{Y}$ & $\mathrm{Y}$ & $\mathrm{Y}$ & $\mathrm{Y}$ & $\mathrm{Y}$ \\
\hline
\end{tabular}

Notes: Standard errors are in parentheses and clustered at the city level. Asterisks, ***, ** and *, indicate the $1 \%, 5 \%$ and $10 \%$ significance levels, respectively. 
Table 7. OLS Estimates of the Association between PM $_{10}$ and Mortality

\begin{tabular}{|c|c|c|c|}
\hline \multirow[b]{2}{*}{ Year } & \multicolumn{3}{|c|}{ Standardized Monthly Mortality (per 100,000 people) } \\
\hline & (1) & (2) & (3) \\
\hline \multirow[t]{2}{*}{2006} & 0.007 & $-0.064 * * *$ & $-0.066 * * *$ \\
\hline & $(0.018)$ & $(0.023)$ & $(0.023)$ \\
\hline \multirow[t]{2}{*}{2007} & 0.0057 & $-0.059 * *$ & $-0.062 * *$ \\
\hline & $(0.022)$ & $(0.028)$ & $(0.029)$ \\
\hline \multirow[t]{2}{*}{2008} & 0.022 & $-0.050 * *$ & $-0.049 * *$ \\
\hline & $(0.021)$ & $(0.023)$ & $(0.024)$ \\
\hline \multirow[t]{2}{*}{2009} & -0.016 & $-0.074 * * *$ & $-0.075^{* * *}$ \\
\hline & $(0.022)$ & $(0.026)$ & $(0.027)$ \\
\hline \multirow[t]{2}{*}{2010} & $0.038 * * *$ & -0.001 & -0.002 \\
\hline & $(0.014)$ & $(0.016)$ & $(0.017)$ \\
\hline \multirow[t]{2}{*}{$2006-2010$} & 0.014 & $-0.045^{* * *}$ & $-0.046 * * *$ \\
\hline & $(0.009)$ & $(0.011)$ & $(0.011)$ \\
\hline Temp and Sq. & $\mathrm{N}$ & $\mathrm{Y}$ & $\mathrm{Y}$ \\
\hline Precipitation & $\mathrm{N}$ & $\mathrm{N}$ & $\mathrm{Y}$ \\
\hline
\end{tabular}

Notes: Standard errors are in parentheses and clustered at the city level. Asterisks, ***, ** and *, indicate the $1 \%, 5 \%$ and $10 \%$ significance levels, respectively. 
Table 8. Fixed Effects Estimates between $\mathbf{P M}_{10}$ and Standardized Mortality

\begin{tabular}{|c|c|c|c|c|c|c|c|c|}
\hline & \multicolumn{4}{|c|}{ Standardized Mortality } & \multicolumn{4}{|c|}{ Standardized CVR Mortality } \\
\hline & (1) & (2) & (3) & (4) & (5) & (6) & (7) & (8) \\
\hline $\mathrm{PM}_{10}$ & $\begin{array}{c}0.054^{* * *} \\
(0.009)\end{array}$ & $\begin{array}{c}0.015 \\
(0.009)\end{array}$ & $\begin{array}{c}0.009 \\
(0.009)\end{array}$ & $\begin{array}{l}0.016^{*} \\
(0.008)\end{array}$ & $\begin{array}{c}0.042^{* * *} \\
(0.007)\end{array}$ & $\begin{array}{c}0.008 \\
(0.005)\end{array}$ & $\begin{array}{l}0.010 * \\
(0.006)\end{array}$ & $\begin{array}{l}0.012^{* *} \\
(0.006)\end{array}$ \\
\hline Weather & $\mathrm{N}$ & $\mathrm{Y}$ & $\mathrm{N}$ & $\mathrm{Y}$ & $\mathrm{N}$ & $\mathrm{Y}$ & $\mathrm{N}$ & $\mathrm{Y}$ \\
\hline City FE & $\mathrm{Y}$ & $\mathrm{Y}$ & $\mathrm{Y}$ & $\mathrm{Y}$ & $\mathrm{Y}$ & $\mathrm{Y}$ & $\mathrm{Y}$ & $\mathrm{Y}$ \\
\hline Month FE & $\mathrm{N}$ & $\mathrm{N}$ & $\mathrm{Y}$ & $\mathrm{Y}$ & $\mathrm{N}$ & $\mathrm{N}$ & $\mathrm{Y}$ & $\mathrm{Y}$ \\
\hline Observations & 1,932 & 1,932 & 1,932 & 1,932 & 1,932 & 1,932 & 1,932 & 1,932 \\
\hline R-Squared & 0.657 & 0.676 & 0.697 & 0.704 & 0.615 & 0.661 & 0.680 & 0.685 \\
\hline
\end{tabular}

Notes: Standard errors are in parentheses and clustered at the city level. Asterisks, ***, ** and *, indicate the $1 \%, 5 \%$ and $10 \%$ significance levels, respectively. 
Table 9. Valuation of the Health Benefits Associated with Air Quality Improvement

\begin{tabular}{|c|c|c|c|c|c|}
\hline & $\begin{array}{l}\text { Location } \\
\qquad(1)\end{array}$ & $\begin{array}{l}\text { Approach } \\
\text { (2) }\end{array}$ & $\begin{array}{c}\text { VSL } \\
\text { (Million } \\
\text { Yuan) } \\
(3) \\
\end{array}$ & $\begin{array}{c}\text { Reduce } \mathrm{PM}_{10} \\
\text { by } 10-\mathrm{ug} / \mathrm{m} 3 \\
\text { (Billion) } \\
(4)\end{array}$ & $\begin{array}{l}\text { Reduce } \mathrm{PM}_{10} \text { to } \\
\text { WHO guideline } \\
\text { (Billion) } \\
\text { (5) }\end{array}$ \\
\hline Hammitt and Zhou (2006) & Beijing & $\mathrm{CV}$ & 0.48 & 94.2 & 753.6 \\
\hline Krupnick et al. (2006) & $\begin{array}{l}\text { Shanghai, } \\
\text { Chongqing }\end{array}$ & $\mathrm{CV}$ & 1.4 & 274.7 & 2197.6 \\
\hline Wang and Mullahy (2006) & Chongqing & $\mathrm{CV}$ & 0.286 & 56.1 & 448.8 \\
\hline Guo and Hammitt (2009) & National & HW & $0.24 \sim 0.8$ & $47.1 \sim 157$ & $376.8 \sim 1256.0$ \\
\hline Qin, Li, and Liu (2013) & National & HW & $\begin{array}{c}1.81 \text { (full) } \\
3.84 \text { (urban) }\end{array}$ & $\begin{array}{l}355.2 \\
753.9\end{array}$ & $\begin{array}{l}2681.6 \\
6031.2\end{array}$ \\
\hline World Bank (2007) & $\mathrm{n} / \mathrm{a}$ & $\mathrm{CV}$ & 1 & 196.2 & 1570.2 \\
\hline
\end{tabular}

Source: Authors' calculation. CV: contingent valuation approach. HW: hedonic wage approach. 


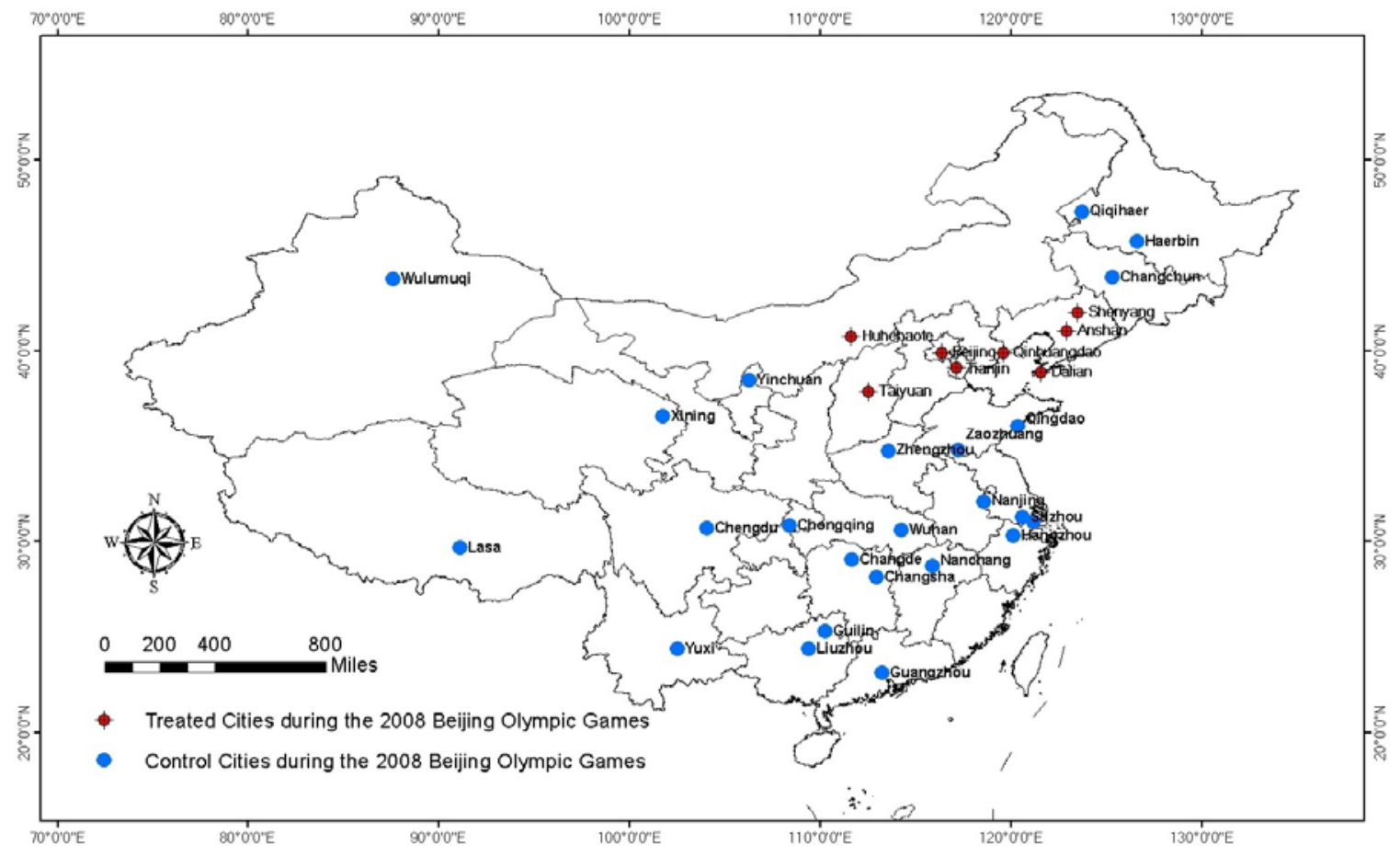

Figure 1. Geographical Distribution of Sampled Urban Cities in China 


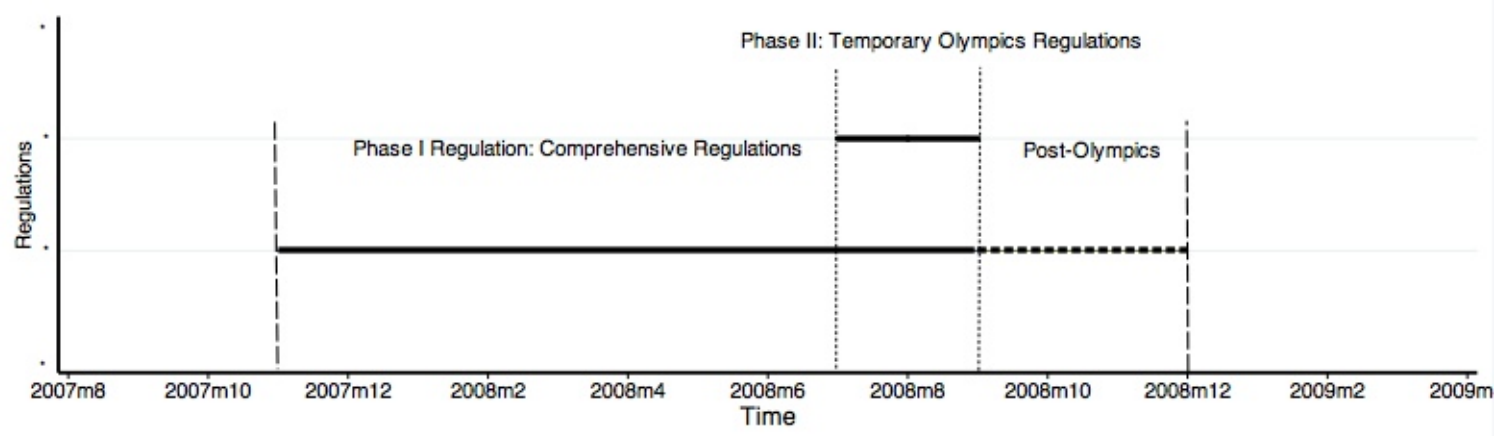

Figure 2. The Timeline of Air Pollution Regulations during the BOG08

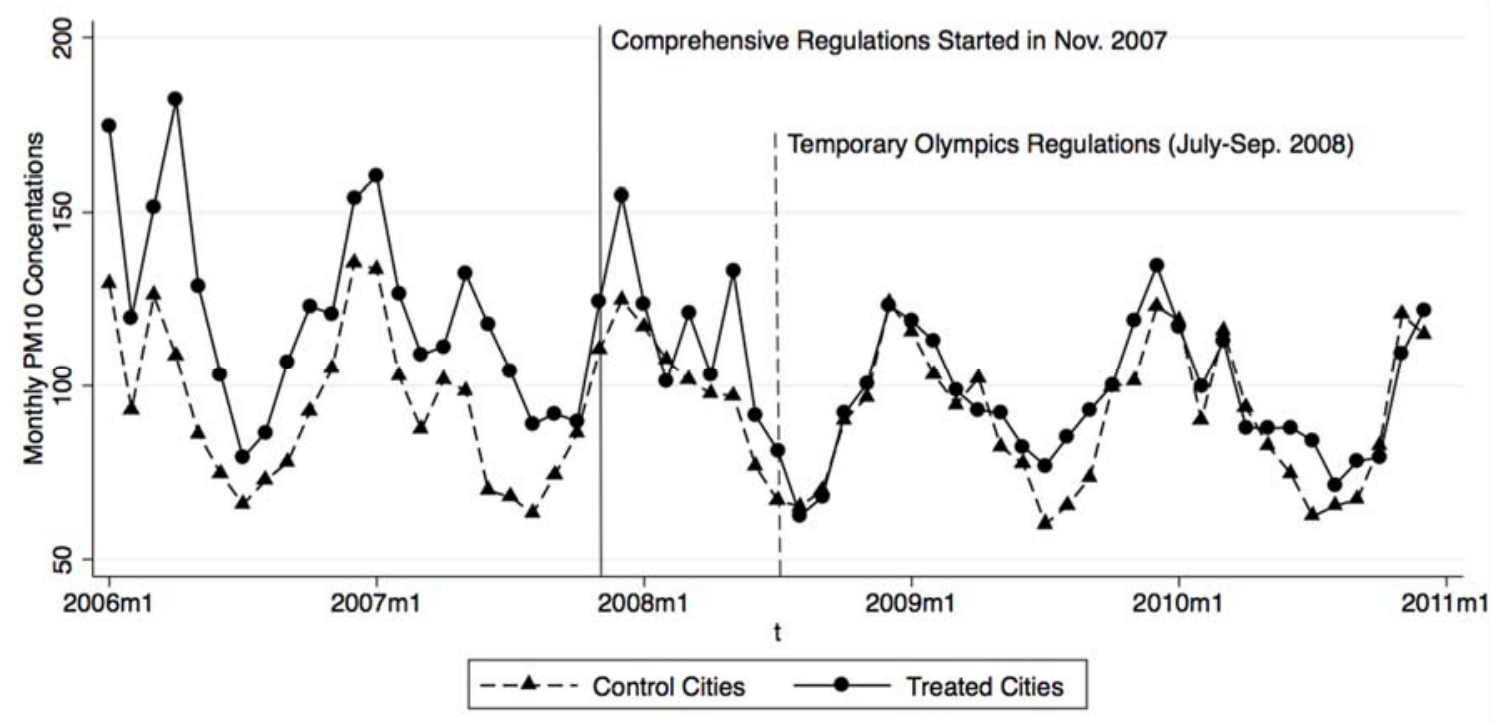

Figure 3. Monthly PM10 Concentrations in Treatment Group and Control Group 


\section{LOWESS Smoother}

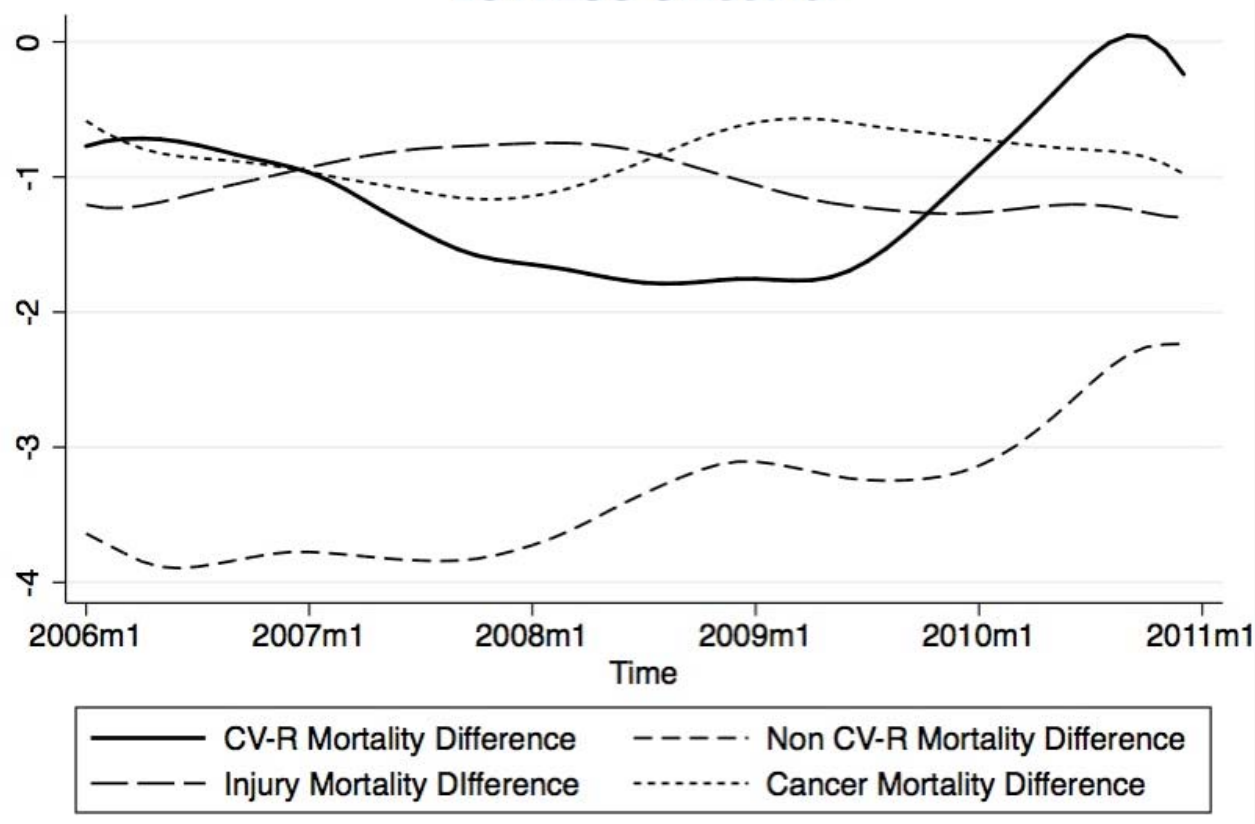

Figure 4. Mortality Differences between the Treatment Cities and Control Cities

Note: The U-shaped solid line shows that CVR mortality difference decreased during the BOG08. 


\section{For Online Publication}

\section{Appendix A. Construction of the Air Pollution Index (API) and Calculation of PM10 Concentrations}

The API is constructed based on the concentrations of three atmospheric pollutants, namely sulfur dioxide $\left(\mathrm{SO}_{2}\right)$, nitrogen dioxide $\left(\mathrm{NO}_{2}\right)$, and suspended particulates of 10 micrometers or less $\left(P M_{10}\right)$ measured at the monitoring stations throughout each city. It is a proxy measure of the ambient air quality. The API indicates the maximum concentration of the three pollutants. Table A.1 shows the relationship between the API and the concentrations of the three air pollutants.

Table A.1 The Relationship between the API and Air Pollutant Concentrations

\begin{tabular}{lllll}
\hline API & $\mathrm{SO}_{2}$ & $\mathrm{NO}_{2}$ & $\mathrm{PM}_{10}$ & Air Quality Levels \\
\hline $0-50$ & $0-0.05$ & $0-0.08$ & $0-0.05$ & Excellent \\
$50-100$ & $0.05-0.15$ & $0.08-0.12$ & $0.05-0.15$ & Good \\
$100-200$ & $0.15-0.8$ & $0.12-0.28$ & $0.15-0.35$ & Slightly Polluted \\
$200-300$ & $0.8-1.6$ & $0.28-0.565$ & $0.35-0.42$ & Moderately Polluted \\
$300-400$ & $1.6-2.1$ & $0.565-0.75$ & $0.42-0.5$ & Severely Polluted \\
$400-500$ & $2.1-2.62$ & $0.75-0.94$ & $0.5-0.6$ & Severely Polluted \\
\hline
\end{tabular}

Notes: Pollutant concentration is measured by $\mathrm{mg} / \mathrm{m}^{3}$. The last column is the official air quality description based on the API

The API is constructed in four steps. First, measure the daily average concentration of each pollutant. Second, for each pollutant, look up its corresponding concentration interval in Table A.1. Third, calculate the pollution index (PI) of each pollutant linearly. Finally, take the maximum of all pollution indices and define it as the API.

For example, assume the concentrations of the three pollutants are: $C_{\mathrm{SO}_{2}}=0.07 \mathrm{mg} / \mathrm{m}^{3}$, $C_{\mathrm{NO}_{2}}=0.10 \mathrm{mg} / \mathrm{m}^{3}$, and $C_{P M_{10}}=0.30 \mathrm{mg} / \mathrm{m}^{3}$. Then, using Table A.1 we find that the concentrations of $\mathrm{SO}_{2}$ and $\mathrm{NO}_{2}$ are in the interval [50,100] while the $P M_{10}$ concentration falls 
into the interval $[100,200]$. Within each interval we can calculate the PI of each pollutant linearly:

$$
\begin{aligned}
& P I_{S O_{2}}=\frac{100-50}{0.15-0.05} *(0.07-0.05)+50=60 \\
& P I_{N O_{2}}=\frac{100-50}{0.12-0.08} *(0.10-0.08)+50=75 \\
& P I_{P M_{10}}=\frac{200-100}{0.35-0.15} *(0.30-0.15)+100=175
\end{aligned}
$$

Then the $A P I=\max \left[P I_{S O_{2}}, P I_{N O_{2}}, P I_{P M_{10}}\right\}=175$ and $P M_{10}$ is called the primary pollutant. According to the standards of the MEP, an API below 50 is defined as "excellent” air quality, 50-100 as “good”, 100-200 as “slightly polluted”, 200-300 as “moderately polluted” and above 300 as "severely polluted.” 


\section{For Online Publication}

\section{Appendix B. Standardized Mortality Rates}

Age adjustment (standardization) allows us to compare mortality rates in different regions with different age structures.

People are divided into 19 age groups: 0, 1, 2-5, 6-10, 11-15..., 75-80, 81-85, and older than 85. For each age group at each surveillance point, the age-group-specific mortality is calculated by:

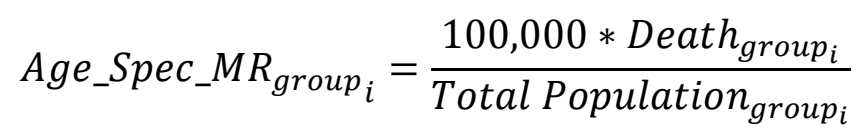

The standardized mortality rate for a specific death surveillance location is calculated as:

$$
S t d \_M R=\sum_{k}\left(\text { Population Weight } \text { group }_{i} * \text { Age_Spec_MR } R_{\text {group }}\right)
$$

We use the population weights from China's 2000 Census. 


\section{For Online Publication}

\section{Appendix C. Regression Results for API}

This Appendix shows the estimates using the API as the measurement of air pollution.

Table C.1 The Effect of the API on Mortality

\begin{tabular}{lcccccc}
\hline & \multicolumn{5}{c}{ API } & \multicolumn{5}{c}{ Standardized Monthly Mortality } \\
\hline \multirow{2}{*}{ Regulated } & $(1)$ & $(2)$ & $(3)$ & $(4)$ & $(5)$ & $(6)$ \\
& $-3.238^{* *}$ & $-3.236^{* *}$ & $-3.206^{* *}$ & & & \\
Traffic Control & $(1.380)$ & $(1.352)$ & $(1.324)$ & & & \\
& $-11.39^{* *}$ & $-12.58^{* * *}$ & $-12.03^{* * *}$ & & & \\
API & $(4.626)$ & $(4.522)$ & $(4.429)$ & & & \\
& & & & $0.570^{* *}$ & $0.468^{* *}$ & $0.472^{* *}$ \\
Temp and Sq. & $\mathrm{N}$ & $\mathrm{Y}$ & $\mathrm{Y}$ & $\mathrm{N}$ & $\mathrm{Y}$ & $\mathrm{Y}$ \\
Precipitation & $\mathrm{N}$ & $\mathrm{N}$ & $\mathrm{Y}$ & $\mathrm{N}$ & $\mathrm{N}$ & $\mathrm{Y}$ \\
City FE & $\mathrm{Y}$ & $\mathrm{Y}$ & $\mathrm{Y}$ & $\mathrm{Y}$ & $\mathrm{Y}$ & $\mathrm{Y}$ \\
Month FE & $\mathrm{Y}$ & $\mathrm{Y}$ & $\mathrm{Y}$ & $\mathrm{Y}$ & $\mathrm{Y}$ & $\mathrm{Y}$ \\
\hline Observations & 1,932 & 1,932 & 1,932 & 1,932 & 1,932 & 1,932 \\
R-Squared & 0.626 & 0.648 & 0.650 & 0.457 & 0.564 & 0.561 \\
\hline \multicolumn{7}{l}{ Notes: Standard errors are in parentheses and clustered at the city level. Asterisks, ***, } \\
** and *, indicate the 1\%, 5\% and 10\% significance levels, respectively. &
\end{tabular}


Table C.2 The Effect of the API on Disease-Specific Mortalities

\begin{tabular}{lcccc}
\hline \multicolumn{4}{c}{ Standardized Monthly Mortality (per 100,000 people) } \\
\hline & CVR & Non-CVR & Injury & Cancer \\
& Mean=16.106 & Mean=19.644 & Mean = 2.534 & Mean=9.067 \\
& $(1)$ & $(2)$ & $(3)$ & $(4)$ \\
API & $0.327^{* *}$ & 0.145 & -0.015 & 0.096 \\
& $(0.152)$ & $(0.143)$ & $(0.026)$ & $(0.061)$ \\
\hline Weather & $\mathrm{Y}$ & $\mathrm{Y}$ & $\mathrm{Y}$ & $\mathrm{Y}$ \\
City FE & $\mathrm{Y}$ & $\mathrm{Y}$ & $\mathrm{Y}$ & $\mathrm{Y}$ \\
Month FE & $\mathrm{Y}$ & $\mathrm{Y}$ & $\mathrm{Y}$ & $\mathrm{Y}$ \\
\hline
\end{tabular}

Notes: Standard errors are in parentheses and clustered at the city level. Asterisks, ${ }^{* * *},{ }^{* *}$ and *, indicate the $1 \%, 5 \%$ and $10 \%$ significance levels, respectively. 
Table C.3. Robustness Check I: Choices of Different End Times

\begin{tabular}{ccc}
\hline & API Coef. on Mort. & API Coef. on CVR Mort. \\
\hline Different End Times of Regulations & & \\
September of 2008 & $\left(0.392^{* *}\right.$ & $0.268^{* *}$ \\
October of 2008 & $0.423^{* *}$ & $(0.127)$ \\
& $(0.200)$ & $0.285^{* *}$ \\
November of 2008 & $0.447^{* *}$ & $(0.134)$ \\
& $(0.218)$ & $0.305^{* *}$ \\
December of 2008 & $\mathbf{0 . 4 7 2 * *}$ & $(0.143)$ \\
Janurary of 2009 & $\mathbf{( 0 . 2 3 8 )}$ & $\mathbf{0 . 3 2 7 ^ { * * }}$ \\
& $0.450^{*}$ & $\mathbf{0 . 1 5 2 )}$ \\
Feburary of 2009 & $(0.233)$ & $0.316^{* *}$ \\
& $0.436^{*}$ & $(0.147)$ \\
March of 2009 & $(0.231)$ & $0.321^{* *}$ \\
April of 2009 & $0.435^{*}$ & $(0.144)$ \\
& $(0.226)$ & $0.325^{* *}$ \\
\hline
\end{tabular}

Notes: Weather controls, city-district fixed-effects and year-month fixed-effects are included in all regressions. Standard errors are in parentheses and clustered at the city level. Asterisks, ***,** and *, indicate the $1 \%, 5 \%$ and $10 \%$ significance levels, respectively. 
Table C.4. Robustness Check II: the API and Mortality

\begin{tabular}{lcccccc}
\hline & \multicolumn{3}{c}{ API Coef. on Mortality } & \multicolumn{3}{c}{ API Coef. on CVR Mortality } \\
\cline { 2 - 7 } & $(1)$ & $(2)$ & $(3)$ & $(4)$ & $(5)$ & $(6)$ \\
Without 07/08 2008 Data & $0.476^{*}$ & $0.455^{*}$ & $0.465^{*}$ & $0.323^{* *}$ & $0.313^{* *}$ & $0.322^{* *}$ \\
& $(0.266)$ & $(0.256)$ & $(0.266)$ & $(0.157)$ & $(0.155)$ & $(0.162)$ \\
With Regional Trends & $0.586^{* *}$ & $0.466^{*}$ & $0.471^{*}$ & $0.396^{* *}$ & $0.326^{* *}$ & $0.332^{* *}$ \\
& $(0.298)$ & $(0.246)$ & $(0.252)$ & $(0.190)$ & $(0.161)$ & $(0.165)$ \\
With Socioeconomic Var. & $0.487^{* *}$ & $0.409^{* *}$ & $0.411^{* *}$ & $0.289^{*}$ & $0.243^{*}$ & $0.245^{*}$ \\
& $(0.226)$ & $(0.194)$ & $(0.200)$ & $(0.149)$ & $(0.128)$ & $(0.132)$ \\
\hline
\end{tabular}

Notes: Standard errors are in parentheses and clustered at the city level. Asterisks, ${ }^{* * *}, * *$ and $*$, indicate the $1 \%, 5 \%$ and $10 \%$ significance levels, respectively. 
Table C.5. OLS Estimates of the Association between the API and Mortality

\begin{tabular}{lccc}
\hline & \multicolumn{3}{c}{ Standardized Monthly Mortality (per 100,000 people) } \\
\cline { 2 - 4 } Year & $(1)$ & $(2)$ & $(3)$ \\
\cline { 2 - 4 } 2006 & 0.013 & $-0.120^{* * *}$ & $-0.122^{* * *}$ \\
& $(0.033)$ & $(0.043)$ & $(0.045)$ \\
2007 & 0.012 & $-0.108^{*}$ & $-0.114^{* *}$ \\
& $(0.043)$ & $(0.056)$ & $(0.058)$ \\
2008 & 0.026 & $-0.114^{* *}$ & $-0.111^{* *}$ \\
& $(0.043)$ & $(0.049)$ & $(0.049)$ \\
2009 & -0.044 & $-0.158^{* * *}$ & $-0.159^{* * *}$ \\
& $(0.045)$ & $(0.052)$ & $(0.054)$ \\
2010 & $0.077^{* * *}$ & -0.0002 & -0.002 \\
& $(0.028)$ & $(0.033)$ & $(0.033)$ \\
& 0.022 & $-0.091^{* * *}$ & $-0.093^{* * *}$ \\
& $(0.018)$ & $(0.022)$ & $(0.023)$ \\
\hline
\end{tabular}

\begin{tabular}{llll}
\hline Temp and Sq. & N & Y & Y \\
Precipitation & N & N & Y \\
\hline
\end{tabular}

Notes: Standard errors are in parentheses and clustered at the city level. Asterisks, ${ }^{* * *},{ }^{* *}$ and $*$, indicate the $1 \%, 5 \%$ and $10 \%$ significance levels, respectively. 
Table C.6. Fixed Effects Estimates between the API and Standardized Mortality

\begin{tabular}{lcccccccc}
\hline & \multicolumn{3}{c}{ Standardized Mortality } & \multicolumn{5}{c}{ Standardized CVR Mortality } \\
\cline { 2 - 9 } API & $(1)$ & $(2)$ & $(3)$ & $(4)$ & $(5)$ & $(6)$ & $(7)$ & $(8)$ \\
\cline { 2 - 9 } & $0.106^{* * *}$ & $0.033^{*}$ & 0.023 & $0.037^{* *}$ & $0.081^{* * *}$ & $0.016^{*}$ & $0.019^{*}$ & $0.024^{* *}$ \\
& $(0.018)$ & $(0.018)$ & $(0.017)$ & $(0.016)$ & $(0.013)$ & $(0.009)$ & $(0.010)$ & $(0.011)$ \\
\hline Weather & $\mathrm{N}$ & $\mathrm{Y}$ & $\mathrm{N}$ & $\mathrm{Y}$ & $\mathrm{N}$ & $\mathrm{Y}$ & $\mathrm{N}$ & $\mathrm{Y}$ \\
City FE & $\mathrm{Y}$ & $\mathrm{Y}$ & $\mathrm{Y}$ & $\mathrm{Y}$ & $\mathrm{Y}$ & $\mathrm{Y}$ & $\mathrm{Y}$ & $\mathrm{Y}$ \\
Month FE & $\mathrm{N}$ & $\mathrm{N}$ & $\mathrm{Y}$ & $\mathrm{Y}$ & $\mathrm{N}$ & $\mathrm{N}$ & $\mathrm{Y}$ & $\mathrm{Y}$ \\
\hline
\end{tabular}

Notes: Standard errors are in parentheses and clustered at the city level. Asterisks, ${ }^{* * *},{ }^{* *}$ and ${ }^{*}$, indicate the $1 \%, 5 \%$ and $10 \%$ significance levels, respectively. 